\title{
Discussão do desempenho da envoltória de uma passive house adaptada à zona bioclimática 2 em acordo com o RTQ-R
}

\author{
Discussion of a passive house envelope's performance \\ adaptaded to Bioclimatic Zone 2 according to the RTQ-R
}

\section{Renata Dalbem \\ Eduardo Grala da Cunha \\ Romeu Vicente \\ António José Figueiredo \\ Antônio César Silveira Baptista da Silva}

\section{Resumo}

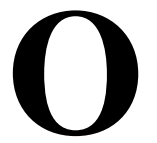

elevado consumo energético do setor das edificações e a consequente emissão de gases de efeito estufa levou a União Europeia a publicar, em 2010, a Diretiva 2010/31/EU, que estabelece que até ao final de 2020 todas as novas edificações deverão ser de balanço energético quase nulo (nZEB). Um caminho possível para alcançar essa meta é a aplicação do conceito Passive House. $\mathrm{O}$ artigo tem o objetivo de analisar o nível de eficiência da envoltória de uma Passive House pelo método de simulação do Regulamento Técnico da Qualidade para o Nível de Eficiência Energética de Edificações Residenciais (RTQ-R). A análise é realizada para a edificação configurada de acordo com o RTQ-R (ventilada naturalmente e condicionada artificialmente), que utiliza o sistema de ventilação mecânica com recuperador de calor (MVHR). Na primeira situação a edificação obteve classificação nível B, devido ao alto consumo do condicionador de ar para aquecimento, e quando utilizado o sistema MVHR a edificação obteve classificação nível A. Em uma análise comparativa do consumo de energia, o sistema MVHR apresentou economia de 56,63\% em relação ao condicionador de ar. Assim, o estudo comprovou a aplicação, sob o enfoque energético, do conceito Passive House para a Zona Bioclimática 2 (ZB2).

Renata Dalbem Universidade Federal de Pelotas Pelotas - RS - Brasil

Eduardo Grala da Cunha Universidade Federal de Pelotas Pelotas - RS - Brasil

Romeu Vicente Universidade de Aveiro Aveiro - Portugal

António José Figueiredo Universidade de Aveiro Aveiro - Portugal

Antônio César Silveira Baptista

da Silva

Universidade Federal de Pelotas Pelotas - RS - Brasil

Recebido em 26/03/16 Aceito em 02/09/16
Palavras-chaves: Eficiência energética. Passive House. Recuperação de calor. RTQ-R. Simulação termoenergética.

\section{Abstract}

The building sector's high energy consumption and the consequent emissions of Directive, determining that by the end of 2020 all new buildings should be nearly Zero Energy Buildings (nZEB). One possible way to achieve this goal is the implementation of the Passive House concept. The aim of this paper is to analyse the efficiency level of the envelope of a Passive House through using the simulation method RTQ-R (Technical Code of the Quality of the Energy Efficiency Level of Residential Buildings). The analysis is performed for the building according to the code's assumptions (naturally ventilated and artificially air conditioned), and using a mechanical ventilation system with heat recovery capacity (MVHR). Firstly, the building was classified as level B, due to the air conditioner's high consumption for heating, and, when using the MVHR system, the building was classified as Level A. In a comparative analysis of energy consumption, the system showed an economy of $56.63 \%$ for the MVHR when compared with the air conditioning system. Thus, this study has proven the success of the application of the Passive House concept for bioclimatic zone 2 (ZB2).

Keywords: Energy efficiency. Passive House. Heat recovery. RTQ-R. Dynamic building simulation. greenhouse gases has led the European Union to publish, in 2010, the 2010/31/EU 


\section{Introdução}

De acordo com a Agência Internacional de Energia (INTERNATIONAL..., 2016b), as edificações são responsáveis mundialmente por $40 \%$ do consumo de energia primária e por $24 \%$ da emissão de gases com efeito de estufa. O Brasil é o sexto país que mais consome energia primária no mundo, perdendo apenas para a China, Estados Unidos, Índia, Rússia e Japão (INTERNATIONAL..., 2016a).

No Brasil, segundo o Balanço Energético Nacional (BEN) de 2015, as edificações representam 50\% do consumo de energia elétrica, sendo o setor residencial o maior consumidor, responsável por $24,9 \%$, seguido do setor comercial, com $17,1 \%$, e do setor público, com 8\% (EMPRESA..., 2015). Em uma edificação residencial, considerando a média entre as regiões do Brasil, 27\% do consumo de energia é atribuído aos equipamentos de refrigeração (geladeira e freezer); $24 \%$ ao aquecimento de água; $20 \%$ ao condicionador de ar; $14 \%$ à iluminação, e $15,5 \%$ representam o consumo de energia de outros equipamentos (LAMBERTS; DUTRA; PEREIRA, 2014).

Em 2010, a União Europeia publicou a Diretiva 2010/31/UE (PARLAMENTO..., 2010), que estabeleceu as metas a serem alcançadas pelos Estados-membros até o final de 2020, de modo a produzir edificações com balanço de energia quase nulo ( $n Z E B$ - nearly zero energy buildings). Foi estabelecido que após 31 de dezembro de 2018 as novas edificações públicas deverão ter balanço de energia quase nulo $(n Z E B)$ e que até 31 de dezembro de 2020 essa regra valerá para todas as novas edificações, com uma previsão de redução de $20 \%$ do consumo de energia. Essa meta ambiciosa pode ser alcançada através da aplicação do conceito Passive House, já testado e com grande disseminação na Europa.

A Standard Passive House surgiu na Alemanha em 1988, desenvolvida por Bo Adamson e Wolfgang Feist, com base na construção de edificações com baixo consumo de energia, exigida nos anos 80 para as novas edificações na Suécia e na Dinamarca. O primeiro protótipo foi construído em 1990, na cidade alemã de Darmstadt-Kranichstein (PASSIPEDIA, 2016b). Passive Houses são edificações em que as condições interiores de conforto são mantidas durante todo o ano com consumo mínimo de energia. Para obter a certificação, a edificação deve atender aos seguintes requisitos, estabelecidos pelo $\mathrm{PHI}^{1}$ (2013):

(a) a demanda de energia para aquecimento não deve exceder a $15 \mathrm{kWh} / \mathrm{m}^{2} \mathrm{a}$ ou a carga de aquecimento não deve exceder a $10 \mathrm{~W} / \mathrm{m}^{2}$;

(b) a demanda de energia primária não deve exceder a $120 \mathrm{kWh} / \mathrm{m}^{2} \mathrm{a}$;

(c) a edificação deve ser estanque, cujo resultado do teste de pressurização (INTERNATIONAL..., 2002) não deve ser superior a $0,6 \mathrm{~h}^{-1}$; e

(d) o conforto térmico deve ser atendido para todas as áreas de permanência durante o inverno, bem como no verão, não ultrapassando $10 \%$ das horas do ano a temperatura de $25^{\circ} \mathrm{C}$.

Para a aplicação da norma Passive House em climas quentes, o projeto Passive-On ${ }^{2}$ (2007) elaborou uma proposta de revisão dos requisitos para certificação levando em consideração as variações climáticas:

(a) deve ser atendido um requisito de refrigeração, em que o consumo para refrigeração não deve exceder a $15 \mathrm{kWh} / \mathrm{m}^{2} \mathrm{a}$;

(b) em localizações com condições de projeto com temperaturas acima de $0{ }^{\circ} \mathrm{C}$ o teste de pressurização com um limite de $1,0 \mathrm{~h}^{-1}$ é suficiente para atingir o critério de aquecimento; e

(c) na estação quente a temperatura interior poderá ser de $26^{\circ} \mathrm{C}$, não sendo permitido exceder essa temperatura num intervalo de tempo superior a $10 \%$ das horas do ano.

Os requisitos devem ser verificados utilizando o Passive House Planning Package (PHPP), uma ferramenta desenvolvida pelo PHI que calcula a demanda anual para aquecimento, refrigeração, energia primária e o percentual de sobreaquecimento da edificação (PASSIPEDIA, 2016a).

Uma Passive House deve ser projetada empregando os cinco princípios de projeto, que são: alto nível de isolamento térmico, minimização de pontes térmicas, esquadrias eficientes, estanqueidade e um sistema de ventilação mecânica com recuperador de calor. A certificação Passive House recomenda que todos os elementos da envoltória tenham baixa transmitância térmica

${ }^{1} \mathrm{O}$ Passive House Institute é um instituto de pesquisa independente, que desempenha papel importante no desenvolvimento do conceito Passive House.

${ }^{2}$ Passive-On é um projeto de investigação e disseminação financiado pelo programa SAVE Intelligent Energy da Europa. 0 projeto tem como objetivo promover o conceito Passive House em climas tropicais. 
(U), sendo recomendado um valor inferior a 0,15 $\mathrm{W} / \mathrm{m}^{2} \mathrm{~K}$ (MCLEOD; MEAD; STANDEN, 2016). Segundo o projeto Passive-On (2007), em climas mais amenos a transmitância térmica do envelope pode ser próxima de $0,30 \mathrm{~W} / \mathrm{m}^{2} \mathrm{~K}$.

As pontes térmicas devem ser evitadas ou reduzidas, para evitar possíveis perdas de energia através de pontos vulneráveis no envelope. Qualquer ponte térmica deve ter um valor de transmitância térmica linear $(\Psi)$ inferior a 0,01 W/mK (MCLEOD; MEAD; STANDEN, 2016).

As esquadrias constituem o elemento construtivo energicamente mais frágil das vedações da edificação. De acordo com Wassouf (2014), a transmitância térmica de uma esquadria, que inclui a perda através do vidro, do caixilho e dos espaçadores das chapas de vidro, não deve exceder $0,80 \mathrm{~W} /\left(\mathrm{m}^{2} \mathrm{~K}\right)$. As esquadrias também devem possuir fator solar alto, sendo recomendado ser maior que $50 \%$, possibilitando o aproveitamento da radiação solar no período de inverno. Em climas mais quentes a utilização de um vidro duplo com capa de baixa emissividade e a caixilharia com corte térmico será suficiente para cumprir os requisitos mínimos (INTERNATIONAL..., 2014).

Outro princípio da Passive House é garantir uma elevada estanqueidade ao ar. A edificação deve ter um resultado de teste de pressão inferior a $0,6 \mathrm{~h}^{-1}$ a uma pressão de $50 \mathrm{~Pa}$. Para isso, devem ser utilizadas membranas estanques ao ar, compatibilizadas com cada elemento construtivo; podem ser de madeira, chapas de alumínio ou membranas de vapor, entre outros (MCLEOD; MEAD; STANDEN, 2016).

A ventilação de uma Passive House deve ser feita através de um sistema com recuperação de calor (Mechanical ventilation with heat recovery, $M V H R)$. O princípio desse sistema consiste em reaproveitar o calor contido no ar de exaustão e transferi-lo para o que é introduzido na edificação, através de um permutador de calor misturando o ar fresco que entra com o ar de exaustão, simplesmente efetuando a troca de calor para reduzir a necessidade de aquecimento (MCLEOD; MEAD; STANDEN, 2016). O mesmo processo pode ser utilizado para refrigeração (PACHECO, 2013). O sistema garante a renovação do ar interior, necessária por questões de salubridade do ar interno, para evitar o acúmulo de poluentes internos em concentrações tóxicas (PACHECO, 2013). O sistema deve ser dimensionado de forma a assegurar um fluxo de ar mínimo de $30 \mathrm{~m}^{3} / \mathrm{h}$ de ar por pessoa, para residências, garantindo o conforto higiênico (WASSOUF, 2014). Em climas quentes e úmidos podem ser usados sistemas com recuperação de calor sensível e latente. Reduzir a umidade do ar de entrada reduz o calor armazenado no vapor de água (carga térmica latente), o que resulta na redução do consumo energético em climatização (PACHECO, 2013).

Outros estudos a respeito dos sistemas MVHR vêm sendo realizados nos últimos anos. Gustafsson et al. (2014) realizaram um estudo através de simulação dinâmica, verificando que o sistema MVHR e micro bomba de calor obteve menor consumo de energia para aquecimento em todos os climas analisados. Em um clima frio, Estocolmo e Gdansk, a economia de energia foi de $36 \%$ em relação ao sistema de referência. El Fouih et al. (2012) também comprovaram a eficiência de um sistema MVHR.

Muitos estudos sobre a aplicação do conceito Passive House em diferentes climas são desenvolvidos atualmente. Figueiredo, Kampf e Vicente (2016) realizaram estudos a fim de contribuir com a implementação do conceito Passive House em Portugal. A partir do modelo original de uma edificação residencial, foram realizadas análises de sensibilidade de modo a satisfazer os padrões de referência. Os melhores resultados levaram a uma redução de $62 \%$ no consumo de aquecimento, $72 \%$ no consumo por refrigeração e de $4,4 \%$ na taxa de sobreaquecimento (FIGUEIREDO et al., 2016).

\section{Objetivo}

O objetivo geral deste trabalho é analisar o nível de eficiência energética da envoltória de uma edificação residencial projetada seguindo os preceitos da norma alemã Passive House, na Zona Bioclimática 2, pelo método de simulação do Regulamento Técnico da Qualidade para o Nível de Eficiência Energética de Edificações Residenciais (RTQ-R), utilizando um sistema de condicionador de ar de expansão direta e um sistema MVHR.

\section{Como objetivos específicos destacam-se:}

(a) analisar a influência do setpoint de temperatura de abertura de janelas para o período de ventilação natural (durante o dia) no consumo energético do condicionador de ar (ativo durante a noite), a fim de otimizar a abertura de janelas;

(b) analisar a economia de energia utilizando o sistema MVHR em relação aos casos com condicionador de ar de expansão direta; e

(c) analisar o desempenho térmico da edificação observando as temperaturas internas. 


\section{Método}

$\mathrm{O}$ trabalho foi desenvolvido em três etapas. $\mathrm{Na}$ primeira etapa foi realizada a análise do nível de eficiência da envoltória da edificação pelo método de simulação do RTQ-R (INMETRO, 2012) utilizando-se o software Energy Plus ${ }^{\circledR}$. Foram avaliadas duas condições: com sistema de condicionador de ar de expansão direta e com o sistema MVHR.

$\mathrm{Na}$ segunda etapa realizou-se uma análise de consumo energético, que se dividiu em duas partes. Primeiramente, utilizando o modelo condicionado artificialmente, é realizada uma análise da influência da alteração de setpoint de abertura de janela no período de ventilação natural (das 9 h00min às $21 \mathrm{~h} 00 \mathrm{~min}$ ) no consumo energético do sistema de condicionador de ar (das $21 \mathrm{~h} 00 \mathrm{~min}$ às $09 \mathrm{~h} 00 \mathrm{~min}$ ), variando os setpoints progressivamente para $20^{\circ} \mathrm{C}, 21^{\circ} \mathrm{C}, 22^{\circ} \mathrm{C}, 23^{\circ} \mathrm{C}$ e $24{ }^{\circ} \mathrm{C}$. Após, comparam-se os consumos de energia dos cinco cenários com o sistema MVHR funcionando 24 horas.

$\mathrm{Na}$ terceira etapa analisou-se o desempenho térmico da edificação através dos resultados das temperaturas internas. As análises foram realizadas considerando o período anual e as semanas mais severas de inverno e de verão. Foi estabelecida a faixa de conforto de $20{ }^{\circ} \mathrm{C}$ até $26{ }^{\circ} \mathrm{C}$, que são os limites de aquecimento e refrigeração estabelecidos pela Passive House para climas quentes, assumidos no trabalho como a zona de conforto térmico.

\section{Objeto de estudo}

Foi utilizado como objeto de estudo um projeto arquitetônico de uma edificação residencial desenvolvida na pesquisa "Casa Bioclimática nZEB e Qualidade do Lugar: Entrelaçando experiências: Portugal e Rio Grande do Sul/Brasil", seguindo os cinco princípios da Passive House. Seu desempenho foi verificado em um estudo anterior (DALBEM; FREITAS; CUNHA, 2015), que utilizou o software PHPP e comprovou o atendimento dos requisitos da certificação.

A edificação desenvolvida foi baseada nas estratégias passivas compiladas e aproveitadas no projeto da casa bioclimática de Pouey (2011). A edificação (Figura 1) possui 126,45 $\mathrm{m}^{2}$, distribuídos em dois pavimentos. No térreo estão a cozinha e a sala de estar integradas, solário, dois dormitórios e banheiro, e no pavimento superior, área de trabalho, área técnica e lavabo. O solário foi localizado na orientação norte, possui cobertura e paredes translúcidas, com proteção solar na cobertura que permite aproveitar os ganhos de radiação solar para aquecimento passivo no inverno e bloquear no verão.

Figura 1 - Plantas baixas dos pavimentos térreo e superior
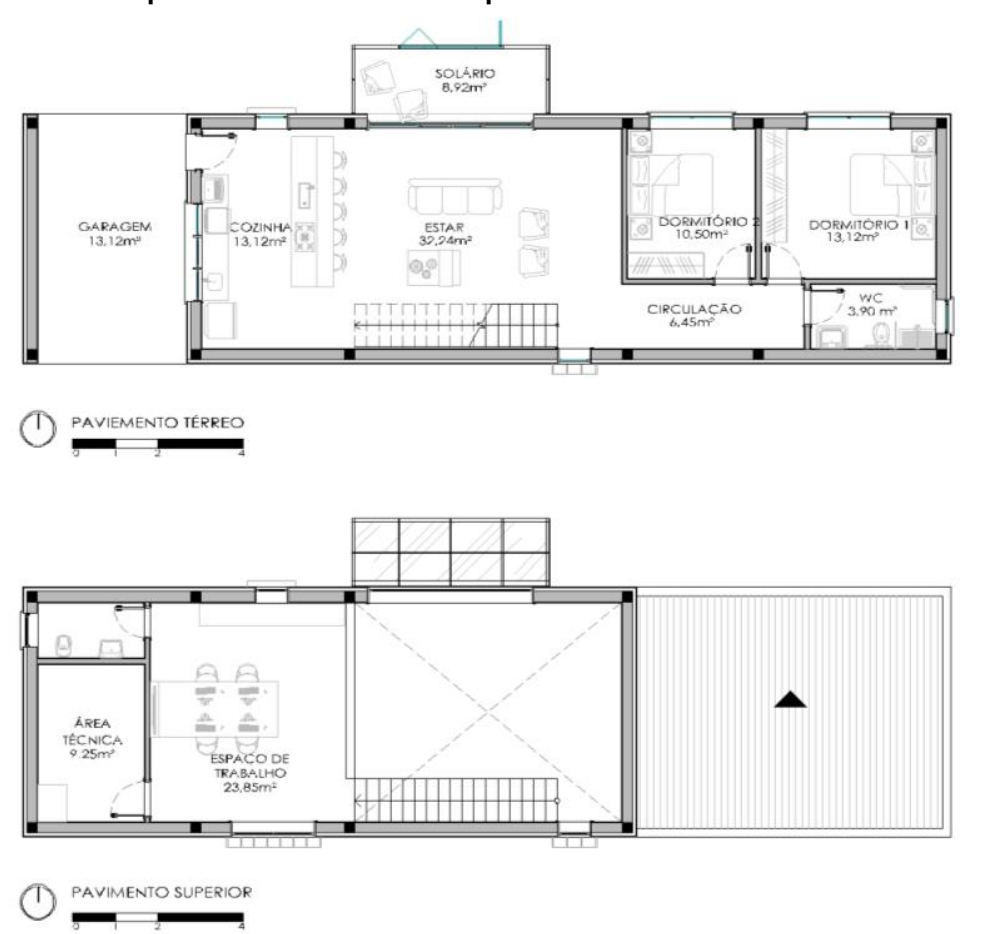

Fonte: Dalbem, Freitas e Cunha (2015). 
O projeto foi orientado sobre o eixo leste-oeste, maximizando a fachada norte e aumentando, assim, os ganhos de radiação solar no inverno. As menores fachadas, para leste e oeste, reduzem os ganhos indesejáveis no verão. A área envidraçada corresponde a 13,56\% da área opaca da edificação, conforme a Tabela 1 . Todas as esquadrias possuem elementos de proteção solar que permitem o controle seletivo da radiação solar.

Os elementos construtivos da edificação foram adotados seguindo os princípios da Standard Passive House, na qual se recomenda uma transmitância térmica próxima a $0,30 \mathrm{~W} /\left(\mathrm{m}^{2} \mathrm{~K}\right)$ para todos os elementos da envolvente opaca em climas quentes. As Tabelas 2 a 5 apresentam a espessura, a condutividade térmica e a resistência térmica dos materiais utilizados, assim como o resultado da transmitância térmica total do elemento de construção, em acordo com a NBR 15220-2 (ABNT, 2005).

As esquadrias adotadas são compostas de vidros duplos com fator solar (FS) de 0,57 e transmitância térmica de $1,5 \mathrm{~W} /\left(\mathrm{m}^{2} \mathrm{~K}\right)$. A caixilharia é em $\mathrm{PVC}$, na cor branca. A edificação tem um sistema de ventilação mecânica com recuperação de calor que exaure $\mathrm{o}$ ar viciado dos ambientes úmidos $\mathrm{e}$ quentes e insufla ar fresco nos ambientes de permanência, conforme o projeto (Figura 2).

O sistema de climatização e ventilação mecânica adotado para o projeto possui eficiência de $84 \%$ de recuperação de calor. O equipamento pode atender a demandas de fluxo de ar de 71 a $293 \mathrm{~m}^{3} / \mathrm{h}$, com um consumo de energia elétrica de $0,29 \mathrm{Wh} / \mathrm{m}^{3}$.

Tabela 1 - Dados da envoltória do projeto

\begin{tabular}{|c|c|c|c|c|c|}
\hline & Total & Norte & Leste & Sul & Oeste \\
\hline Área bruta de parede $\left(\mathrm{m}^{2}\right)$ & 219,95 & 68,64 & 32,98 & 85,35 & 32,98 \\
\hline Área de abertura de janelas $\left(\mathrm{m}^{2}\right)$ & 29,83 & 22,79 & 0,48 & 6,08 & 0,48 \\
\hline Percentual de abertura (\%) & 13,56 & 33,20 & 1,46 & 7,12 & 1,46 \\
\hline
\end{tabular}

Tabela 2 - Composição das paredes externas

\begin{tabular}{|c|c|c|c|c|c|c|}
\hline & & \multicolumn{3}{|l|}{ PAREDES EXTERNAS } & \multirow{2}{*}{$\begin{array}{c}\text { Rsi = 0,13 } \\
\text { R }\left(\mathbf{m}^{2} /(\mathbf{W K})\right) \\
\end{array}$} & \multirow{2}{*}{$\begin{array}{c}\text { Rse }=0,04 \\
\mathbf{U}\left(\mathbf{W} /\left(\mathbf{m}^{2} \mathbf{K}\right)\right)\end{array}$} \\
\hline & \multirow{5}{*}{ IN } & Constituição & e (m) & $\lambda(\mathbf{W} /(\mathbf{m K}))$ & & \\
\hline & & Reboco interno & 0,02 & 1,15 & 0,02 & \multirow{4}{*}{0,31} \\
\hline & & Tijolo térmico Weber & 0,24 & 0,22 & 1,07 & \\
\hline EXT. & & Isolamento térmico - EPS & 0,08 & 0,04 & 2,00 & \\
\hline & & Reboco externo & 0,02 & 1,15 & 0,02 & \\
\hline
\end{tabular}

Fonte: ABNT (2005).

Nota: Legenda:

$$
\begin{aligned}
& \mathrm{e}=\text { espessura; } \\
& \lambda=\text { condutividade térmica; } \\
& \mathrm{R}=\text { resistência térmica; } \mathrm{e} \\
& \mathrm{U}=\text { transmitância térmica. }
\end{aligned}
$$

\begin{tabular}{|c|c|c|c|c|c|c|}
\hline \multirow{6}{*}{ EXT. } & & \multicolumn{3}{|l|}{ PONTES TÉRMICAS } & Rsi $=0,13$ & Rse = 0,04 \\
\hline & \multirow{5}{*}{ INT. } & Constituição & e (m) & $\lambda(\mathbf{W} /(\mathbf{m K}))$ & $\mathbf{R}\left(\mathbf{m}^{2} /(\mathbf{W K})\right)$ & $\mathbf{U}\left(\mathbf{W} /\left(\mathbf{m}^{2} \mathbf{K}\right)\right)$ \\
\hline & & Reboco interno & 0,02 & 1,15 & 0,02 & \multirow{4}{*}{0,43} \\
\hline & & Pilar/Vigas de concreto & 0,24 & 1,75 & 0,14 & \\
\hline & & Isolamento térmico - EPS & 0,08 & 0,04 & 2,00 & \\
\hline & & Reboco externo & 0,02 & 1,15 & 0,02 & \\
\hline
\end{tabular}

Tabela 3 - Composição das pontes térmicas

Fonte: ABNT (2005).

Nota: Legenda:

$\mathrm{e}=$ espessura;
$\lambda=$ condutividade térmica;
$\mathrm{R}=$ resistência térmica; $\mathrm{e}$
$\mathrm{U}=$ transmitância térmica. 
Tabela 4 - Composição laje de piso

\begin{tabular}{|c|c|c|c|c|c|}
\hline & \multicolumn{3}{|l|}{ LAJE DE PISO } & \multirow{2}{*}{$\begin{array}{c}\text { Rsi = 0,17 } \\
\mathbf{R}\left(\mathbf{m}^{2} /(\mathbf{W K})\right)\end{array}$} & \multirow{2}{*}{$\begin{array}{c}\text { Rse }=\mathbf{0 , 1 7} \\
\mathbf{U}\left(\mathbf{W} /\left(\mathbf{m}^{2} \mathbf{K}\right)\right)\end{array}$} \\
\hline & Constituição & e (m) & $\lambda(\mathrm{W} /(\mathrm{mK}))$ & & \\
\hline 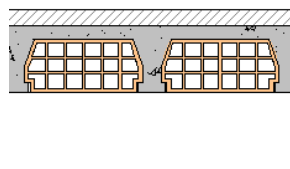 & $\begin{array}{l}\text { Revestimento cerâmico } \\
\text { Argamassa de assentam. } \\
\text { Isolamento térmico } \\
\text { Laje pré-moldada }\end{array}$ & $\begin{array}{l}0,01 \\
0,04 \\
0,08 \\
0,25\end{array}$ & $\begin{array}{c}0,90 \\
1,15 \\
0,04 \\
-\end{array}$ & $\begin{array}{l}0,01 \\
0,02 \\
2,00 \\
0,19\end{array}$ & 0,40 \\
\hline
\end{tabular}

Fonte: ABNT (2005).

Nota: Legenda:

$$
\begin{aligned}
& \mathrm{e}=\text { espessura; } \\
& \lambda=\text { condutividade térmica; } \\
& \mathrm{R}=\text { resistência térmica; } \mathrm{e} \\
& \mathrm{U}=\text { transmitância térmica. }
\end{aligned}
$$

\begin{tabular}{|c|c|c|c|c|c|}
\hline & \multicolumn{3}{|l|}{ COBERTURA } & \multirow{2}{*}{$\begin{array}{c}\text { Rsi = 0,10 } \\
\text { R }\left(\mathbf{m}^{2} /(\mathbf{W K})\right)\end{array}$} & \multirow{2}{*}{$\begin{array}{c}\text { Rse }=\mathbf{0 , 0 4} \\
\mathbf{U}\left(\mathbf{W} /\left(\mathbf{m}^{2} \mathbf{K}\right)\right)\end{array}$} \\
\hline$n$ & Constituição & e (m) & $\lambda(\mathbf{W} /(\mathbf{m K}))$ & & \\
\hline AR & \multirow{3}{*}{$\begin{array}{l}\text { Reboco interno } \\
\text { Laje pré-moldada } \\
\text { Isolamento térmico - EPS } \\
\text { Reboco externo }\end{array}$} & 0,02 & 1,15 & 0,02 & \multirow{3}{*}{0,41} \\
\hline 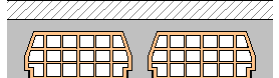 & & $\begin{array}{l}0,25 \\
0,08\end{array}$ & $\begin{array}{c}- \\
0,04\end{array}$ & $\begin{array}{l}0,19 \\
2,00\end{array}$ & \\
\hline & & 0,02 & 1,15 & 0,02 & \\
\hline
\end{tabular}

Tabela 5 - Composição da cobertura

Fonte: ABNT (2005).

Nota: Legenda:

$\mathrm{e}=$ espessura;
$\lambda=$ condutividade térmica;
$\mathrm{R}=$ resistência térmica; $\mathrm{e}$
$\mathrm{U}=$ transmitância térmica.

Figura 2 - Projeto do sistema de ventilação - Pavimentos térreo e superior
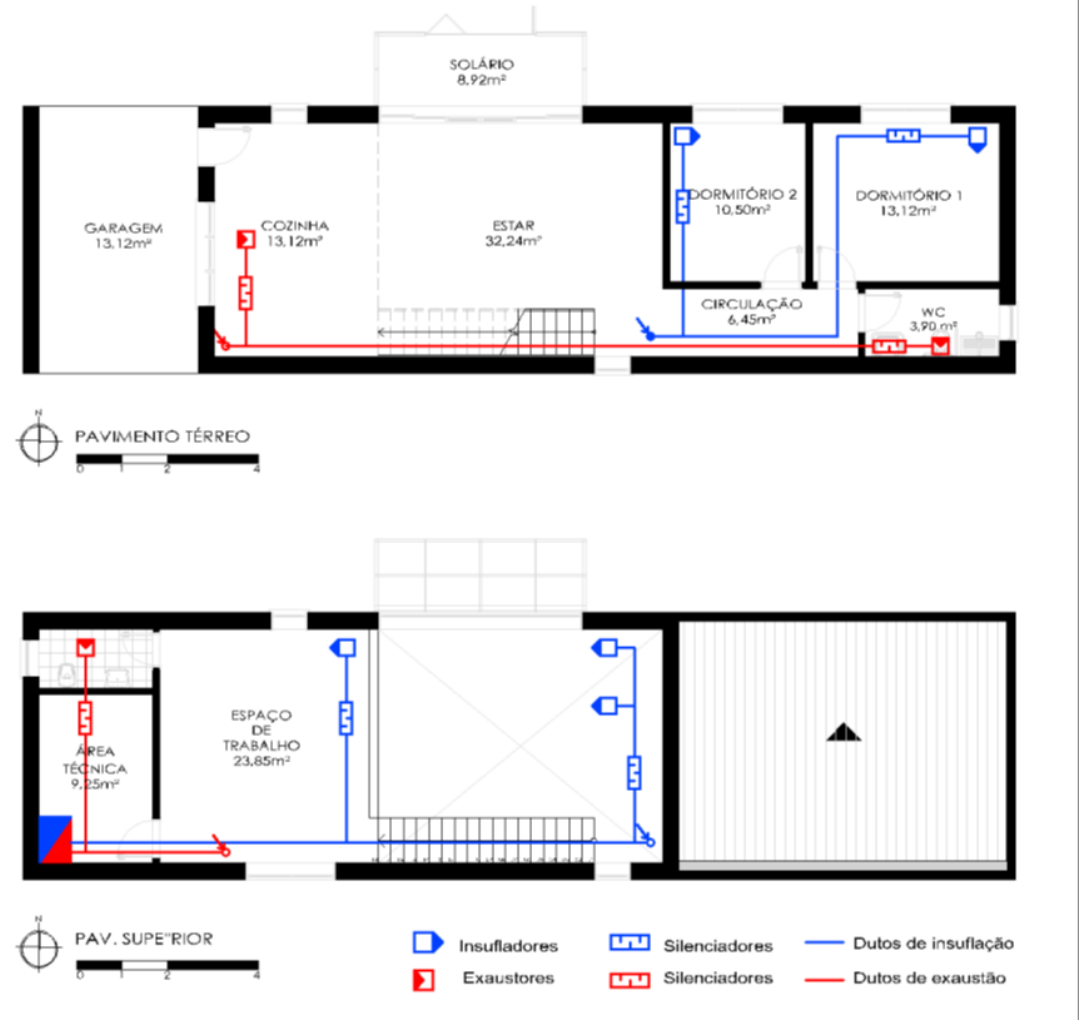

206 Dalbem, R.; Cunha, E. G. da; Vicente, R.; Figueiredo, A. J.; Silva, A. C. S. B. da. 


\section{Dados climáticos}

Como Pelotas, RS, não possui arquivo climático, foi utilizado para a simulação o arquivo climático da cidade de Camaquã, RS - também localizada na Zona Bioclimática 2 (ABNT, 2005) -, que é próxima a Pelotas e possui características climáticas semelhantes. O arquivo climático foi elaborado por Maurício Roriz (ANTAC - GT Conforto e Energia) mediante dados registrados pelo Instituto Nacional de Meteorologia (Inmet) no período de 2001 a 2010. Algumas variáveis climáticas da cidade de Camaquã são apresentadas na Tabela 6.

\section{Modelagem e configuração da edificação em acordo com o RTQ-R}

Para a análise da eficiência da envoltória da edificação pelo método de simulação do RTQ-R foi utilizado o software Energy Plus ${ }^{\circledR}$, versão 8.3.0, que atende a todos os pré-requisitos exigidos pelo RTQ-R. A modelagem da edificação foi desenvolvida na interface gráfica do SketchUp
2015 (Figura 3) utilizando o plugin Legacy Open Studio 1.0.13.

Para a configuração dos modelos foram utilizados os valores padrão apresentados no RTQ-R (INMETRO, 2012) para ocupação, iluminação e uso de equipamentos. O padrão mínimo de ocupação adotado foi o de duas pessoas por dormitório, e na sala, a soma de todos os usuários. As rotinas de ocupação foram configuradas separadamente para os dias de semana e para os fins de semana, conforme descrito nas Figuras $4 \mathrm{e}$ 5 .

A taxa de metabolismo utilizada foi de 81 W/pessoa nos dormitórios e de $108 \mathrm{~W} /$ pessoa na sala/cozinha.

A densidade de potência instalada de iluminação foi de $6 \mathrm{~W} / \mathrm{m}^{2}$ nas salas e de $5 \mathrm{~W} / \mathrm{m}^{2}$ nos dormitórios. As agendas de iluminação foram configuradas separadamente para os dias de semana e para os fins de semana, conforme as Figuras 6 e 7.

\section{Tabela 6 - Dados climáticos de Camaquã (Inmet)}

\begin{tabular}{l|c|c|c|c|c|c|c|c|c|c|c|c}
\hline Médias & Jan & Fev & Mar & Abr & Mai & Jun & Jul & Ago & Set & Out & Nov & Dez \\
\hline TBS média ( $\left.{ }^{\mathbf{O}} \mathbf{C}\right)$ & 23,0 & 22,3 & 21,9 & 18,1 & 15,4 & 12,0 & 14,8 & 13,2 & 14,5 & 17,7 & 20,6 & 21,6 \\
\hline $\begin{array}{l}\text { TBS média das } \\
\left.\text { máx. ( }{ }^{\mathbf{0}} \mathbf{C}\right)\end{array}$ & 36,1 & 34,8 & 33,1 & 32,7 & 30,0 & 21,8 & 28,6 & 26,3 & 30,3 & 31,7 & 30,7 & 34,2 \\
\hline $\begin{array}{l}\text { TBS média das } \\
\text { min. }\left(^{\circ} \mathbf{C}\right)\end{array}$ & 13,2 & 12,5 & 14,5 & 5,8 & 2,4 & 1,1 & 5,0 & 1,2 & 6,0 & 5,7 & 10,4 & 11,5 \\
\hline UR média (\%) & 76 & 83 & 81 & 79 & 85 & 88 & 89 & 86 & 85 & 83 & 80 & 78 \\
\hline $\begin{array}{l}\text { Velocidade média } \\
\text { do vento (m/s) }\end{array}$ & 2,0 & 1,7 & 1,5 & 1,3 & 1,5 & 1,3 & 1,2 & 1,4 & 2,0 & 1,9 & 2,2 & 1,9 \\
\hline
\end{tabular}

Nota: Legenda:

TBS = temperatura de bulbo seco; e

$\mathrm{UR}=$ umidade relativa.

Figura 3 - Modelo do projeto arquitetônico no SketchUp

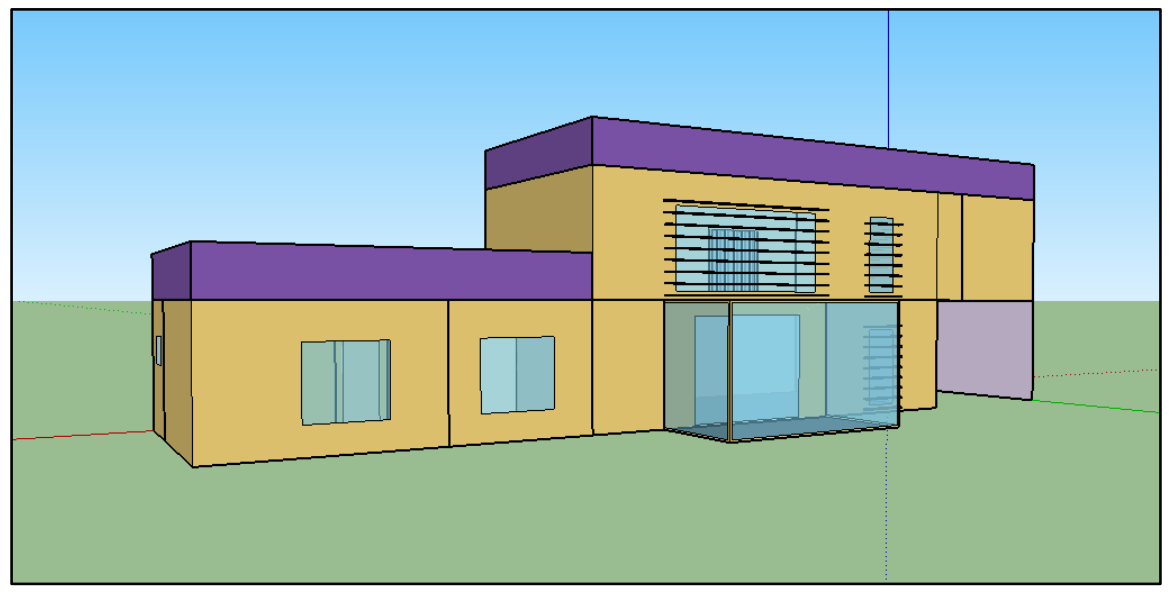


Figura 4 - Padrão de ocupação para dias de semana - porcentagem por horas

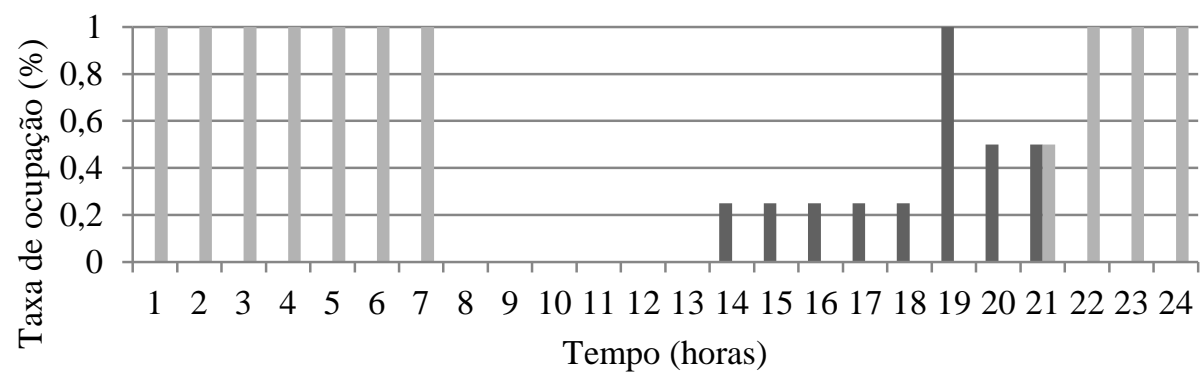

$\square$ Sala

- Dormitórios

Tempo (horas)

Fonte: Inmetro (2012).

Figura 5 - Padrão de ocupação para fins de semana

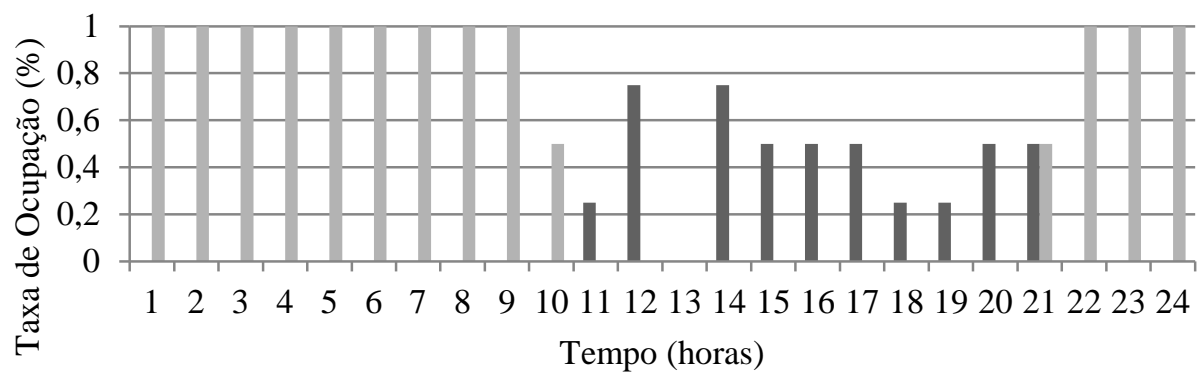

- Sala

Dormitórios

Fonte: Inmetro (2012).

Figura 6 - Padrão de iluminação para os dias de semana

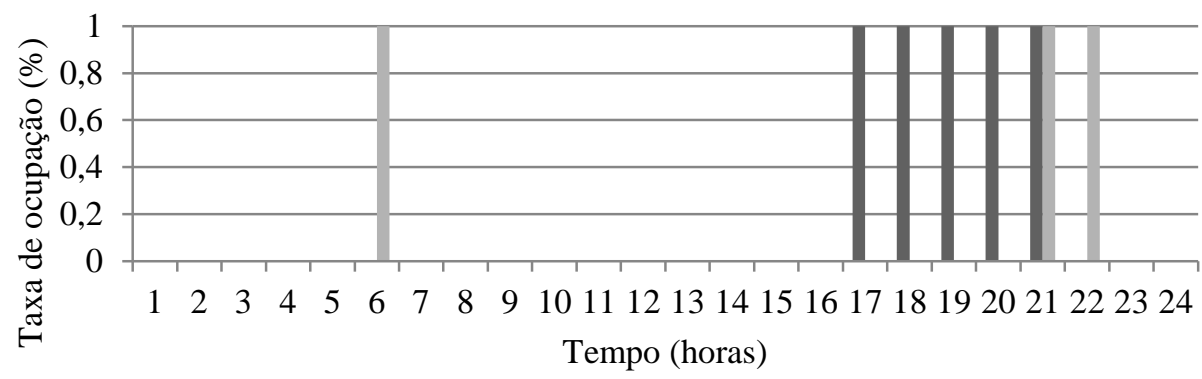

- Sala

Dormitórios

Fonte: Inmetro (2012).

Figura 7 - Padrão de iluminação para os fins de semana

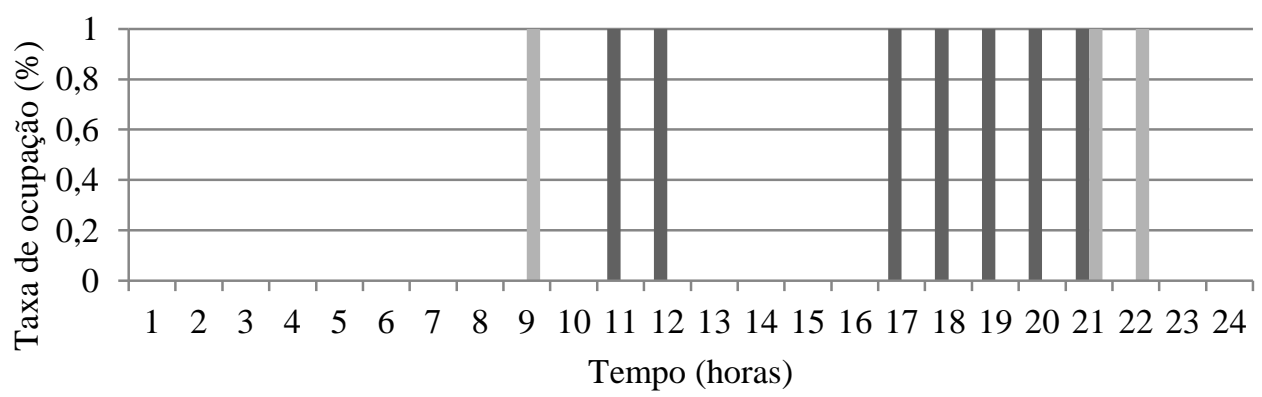

- Sala

Dormitórios

Fonte: Inmetro (2012).

208 Dalbem, R.; Cunha, E. G. da; Vicente, R.; Figueiredo, A. J.; Silva, A. C. S. B. da. 
A densidade de carga interna com equipamentos recomendada é de $1,5 \mathrm{~W} / \mathrm{m}^{2}$ para a sala, considerada no período de $24 \mathrm{~h}$, durante todo o período da simulação.

A temperatura do solo foi determinada utilizandose o programa Slab, vinculado ao EnergyPlus ${ }^{\circledR}$. Para isso foi realizada uma simulação inicial para a verificação das temperaturas médias mensais do ar interno, em que o solo foi considerado sob uma condição adiabática. Em seguida, as temperaturas médias mensais do ar interno obtidas foram configuradas e simuladas com o pré-processador Slab, que corrige as temperaturas médias mensais do solo.

Conforme estabelece o regulamento, foram criados dois modelos-base: modelo ventilado naturalmente e modelo condicionado artificialmente (ventilação natural diurna e condicionador de ar noturno). O período de simulação para os dois modelos compreende as $8.760 \mathrm{~h}$ do ano. $\mathrm{O}$ modelo ventilado naturalmente foi definido conforme o objeto AirFlowNetwork do EnergyPlus ${ }^{\circledR}$, com as configurações de operação de aberturas e setpoint de operação de acordo com o RTQ-R, que recomenda a temperatura de termostato de $20{ }^{\circ} \mathrm{C}$ em condições favoráveis, ou seja, quando a temperatura externa é inferior à temperatura interna. A ventilação natural é configurada para as 24 horas do dia durante todo o período de simulação.

Para o modelo da edificação condicionada artificialmente foi definida a ventilação no período das 9h00min às 21h00min, e condicionamento artificial no período das $21 \mathrm{~h} 00 \mathrm{~min}$ às $9 \mathrm{~h} 00 \mathrm{~min}$. Conforme recomenda o regulamento, foi configurada a temperatura de termostato de refrigeração em $24{ }^{\circ} \mathrm{C}$, e de aquecimento em $22^{\circ} \mathrm{C}$. $\mathrm{O}$ sistema de aquecimento tem COP (coeficiente de performance) de $2,75 \mathrm{~W} / \mathrm{W}$, e o sistema de refrigeração, de 3,00 W/W. A taxa de fluxo de ar por pessoa é de $0,00944 \mathrm{~m}^{3} / \mathrm{s}$. A eficiência do motor é de 0,90, e a do ventilador é de 0,70.

\section{Configuração do modelo utilizando o sistema de ventilação mecânica com recuperador de calor (MVHR)}

O nível de eficiência energética da envoltória também foi avaliado considerando o modelo configurado com um sistema de recuperação de calor (MVHR) ativo durante as 24 horas do dia. Neste modelo não é considerada a ventilação por abertura de janelas, apenas infiltração de $0,6 \mathrm{~h}^{-1}$, valor máximo permitido pela Passive House.

O sistema foi configurado no objeto IdealLoadsAirSystem, do Energy Plus ${ }^{\circledR}$, com um fluxo de ar constante de $0,4 \mathrm{~h}^{-1}$ e com possibilidade de by-pass até uma vazão máxima que garanta uma renovação de $0,8 \mathrm{~h}^{-1}$. A recuperação de calor possui eficiência de $84 \%$, conforme especificado no projeto, e é ativa para um setpoint de temperatura $20-26^{\circ} \mathrm{C}$.

O objeto IdealLoadsAirSystem considera que, quando a temperatura está fora dos limites de setpoint, a climatização é realizada com um sistema de condicionador de ar com coeficiente de performance (COP) de $1 \mathrm{~W} / \mathrm{W}$.

Embora no caso de climatização artificial, considerando o RTQ-R, haja um sistema de condicionador de ar com um COP de 2,75 W/W para aquecimento e de 3,0 W/W para refrigeração, a baixa eficiência do sistema hipotético de climatização do MVHR é uma condição de contorno prejudicial à eficiência do sistema. Essa desvantagem de eficiência de climatização artificial na análise do MVHR foi assumida no trabalho.

\section{Métodos de análise dos resultados}

Nesta seção são apresentados os métodos de análise de resultados, conforme o RTQ-R, de análise de desempenho energético e de consumo de energia para os diferentes modelos.

\section{Enfoque principal: avaliação do nível de eficiência da envoltória de acordo com o RTQ-R}

Para a avaliação do desempenho da envoltória pelo método de simulação do RTQ-R, deve-se comparar o desempenho da edificação sob avaliação com os valores de referência das tabelas de classificação de acordo com a zona bioclimática (PBE EDIFICA, 2016). Também se deve atender aos pré-requisitos estabelecidos quanto ao programa e ao arquivo climático utilizados na simulação (INMETRO, 2012). Para a simulação da edificação ventilada naturalmente, comparam-se os indicadores de graus-hora de resfriamento $\left(\mathrm{GH}_{\mathrm{R}}\right)$ dos ambientes de permanência prolongada com os níveis de eficiência das tabelas de classificação. A temperatura-base para o cálculo dos graus-hora de resfriamento é de $26^{\circ} \mathrm{C}$.

O procedimento da avaliação da edificação condicionada artificialmente compara os consumos relativos para aquecimento $\left(\mathrm{C}_{\mathrm{A}}\right)$ e para refrigeração $\left(C_{R}\right)$ dos ambientes de permanência prolongada com os níveis de eficiência das tabelas de classificação (Tabela 7).

A determinação do equivalente numérico da envoltória é realizada por meio de equações estabelecidas para cada zona bioclimática. Para a 
Zona Bioclimática 2, utiliza-se a Equação 1 (INMETRO, 2012):

EqNumEnv $=0,44 \times E q N u m E n v_{\text {Resfr }}+0,56 \times$ EqNumEnv

Onde:

EqNumEnv: equivalente numérico da envoltória;

EqNumEnv $_{\text {Resfr: }}$ equivalente numérico da envoltória para resfriamento; e

EqNumEnv $_{\mathrm{A}}$ : equivalente numérico da envoltória para aquecimento.

De acordo com a pontuação final obtida no equivalente numérico da envoltória (EqNumEnv) é atribuída uma classificação que varia do nível A (mais eficiente) ao $\mathrm{E}$ (menos eficiente), de acordo com a Tabela 8 .

O mesmo método de classificação é utilizado para a determinação do nível de eficiência energética da envoltória considerando a utilização do sistema de ventilação mecânica com recuperador de calor (MVHR).

\section{Enfoque secundário 1: desempenho energético da edificação climatizada artificialmente}

Neste item foram realizadas duas análises:

(a) estudo de setpoints para abertura de janelas durante o período de ventilação natural no modelo condicionado artificialmente; e

(b) análise do consumo de energia da edificação considerando o sistema MVHR e o sistema de climatização de expansão direta.

No modelo condicionado artificialmente, observando o funcionamento do sistema de condicionador de ar no período noturno, foram feitas variações no setpoint de temperatura para a abertura das janelas, durante o período diurno, progressivamente para $20^{\circ} \mathrm{C}, 21^{\circ} \mathrm{C}, 22^{\circ} \mathrm{C}, 23^{\circ} \mathrm{C}$ e $24{ }^{\circ} \mathrm{C}$, com o objetivo de verificar se o desempenho da edificação durante o dia impactaria no consumo de energia do sistema de condicionamento artificial utilizado à noite. Foram testados, portanto, diferentes setpoints de abertura das janelas ao longo do dia, apresentados na Tabela 9.

Tabela 7 - Classificação pelo método de simulação para a ZB2

\begin{tabular}{|c|c|c|c|c|c|c|c|c|c|c|}
\hline Eficiência & EqNum & \multicolumn{3}{|c|}{ GHR } & \multicolumn{3}{|c|}{ CR $\left(k W h / m^{2} \mathbf{a}\right)$} & \multicolumn{3}{|c|}{$\overline{C A}\left(k W h / m^{2} a\right)$} \\
\hline $\mathrm{A}$ & 5 & & $\mathrm{GHR} \leq$ & 2310 & & $\mathrm{CR} \leq$ & 5,849 & & $\mathrm{CA} \leq$ & 15,591 \\
\hline B & 4 & 2310 & $<\mathrm{GHR} \leq$ & 4396 & 5,849 & $<\mathrm{CR} \leq$ & 11,288 & 15,591 & $<\mathrm{CA} \leq$ & 31,182 \\
\hline $\mathrm{C}$ & 3 & 4396 & $<\mathrm{GHR} \leq$ & 6481 & 11,288 & $<\mathrm{CR} \leq$ & 16,727 & 31,182 & $<\mathrm{CA} \leq$ & 46,772 \\
\hline
\end{tabular}

Fonte: modificada de PBE Edifica (2016).

Tabela 8 - Classificação do nível de eficiência de acordo com a pontuação obtida

\begin{tabular}{c|c}
\hline Pontuação $(\mathbf{P T})$ & Nível de eficiência \\
\hline $\mathrm{PT} \geq 4,5$ & $\mathrm{~A}$ \\
$3,5 \leq \mathrm{PT}<4,5$ & $\mathrm{~B}$ \\
$2,5 \leq \mathrm{PT}<3,5$ & $\mathrm{C}$ \\
$1,5 \leq \mathrm{PT}<2,5$ & $\mathrm{D}$ \\
$\mathrm{PT}<1,5$ & $\mathrm{E}$ \\
\hline
\end{tabular}

Fonte: Inmetro (2012).

Tabela 9 - Cenários analisados alterando-se o setpoint de abertura das janelas

\begin{tabular}{l|c|c|c|c|c}
\hline \multicolumn{1}{c|}{ Período } & Cenário 1 & Cenário 2 & Cenário 3 & Cenário 4 & Cenário 5 \\
\hline Diurno & Ventilação & Ventilação & Ventilação & Ventilação & Ventilação \\
(9h00min às & natural, setpoint & natural, setpoint & natural, setpoint & natural, setpoint & natural, setpoint \\
21 h00min) & $20^{\circ} \mathrm{C}$ & $21^{\circ} \mathrm{C}$ & $22^{\circ} \mathrm{C}$ & $23^{\circ} \mathrm{C}$ & $24^{\circ} \mathrm{C}$ \\
\hline \multirow{2}{*}{ Noturno } & Climatização & Climatização & Climatização & Climatização & Climatização \\
$(21$ h00min às & artificial, & artificial, & artificial, & artificial, & artificial, \\
09h00min) & sistema de & sistema de & sistema de & sistema de & sistema de \\
& expansão direta & expansão direta & expansão direta & expansão direta & expansão direta \\
\hline
\end{tabular}

210 Dalbem, R.; Cunha, E. G. da; Vicente, R.; Figueiredo, A. J.; Silva, A. C. S. B. da. 
Essa análise tem como segundo objetivo comparar o consumo de climatização artificial da edificação com o sistema de ventilação mecânica com recuperação de calor, o que caracteriza dois cenários. No primeiro temos o MVHR integrado com sistema de climatização artificial de baixa eficiência, com coeficiente de performance (COP) de 1 W/W para ambos, aquecimento e refrigeração. No segundo cenário temos o sistema de climatização de expansão direta com COP de 2,75 W/W para aquecimento e de 3,0 W/W para refrigeração, como preconiza o RTQ-R. Na Tabela 10 os dois cenários de análise são apresentados.

Outro aspecto importante de ser mencionado é referente ao período de climatização da edificação. Enquanto no cenário do MVHR a edificação é climatizada 24 horas por dia, sempre na faixa de $20{ }^{\circ} \mathrm{C}$ a $26{ }^{\circ} \mathrm{C}$, no caso do sistema de condicionador de ar de expansão direta a edificação é climatizada apenas das $21 \mathrm{~h} 00 \mathrm{~min}$ às 9h00min, se necessário, observando o que preconiza o RTQ-R. Nessa abordagem, embora se esteja comparando as estratégias de climatização dos espaços internos, não são garantidas as mesmas condições de conforto térmico. Essas configurações colocam o sistema de MVHR em desvantagem no que diz respeito ao consumo energético da edificação para climatização artificial, já que o sistema opera 24 horas por dia com um sistema de climatização, quando a condição interna extrapola os setpoints de aquecimento e refrigeração, com uma eficiência de $1 \mathrm{~W} / \mathrm{W}$

\section{Enfoque secundário 2: desempenho térmico, análise das temperaturas internas}

É avaliado o desempenho térmico da edificação através da análise das variações das temperaturas operativas internas durante o ano todo e durante as semanas mais severas de inverno e verão. Foi estabelecida uma faixa de conforto com temperaturas entre $20{ }^{\circ} \mathrm{C}$ e $26{ }^{\circ} \mathrm{C}$, que são os limites estabelecidos pela Passive House. Na Tabela 11 são apresentados os três cenários avaliados no estudo das temperaturas internas.

\section{Resultados}

Nesta seção são analisados os resultados do nível de eficiência energética da envoltória do modelo de acordo com o RTQ-R e do modelo com sistema de ventilação mecânica com recuperador de calor. Também são analisados os consumos de energia e desempenho térmico dos modelos.

\section{Avaliação da envoltória em acordo com o RTQ-R}

A partir do modelo ventilado naturalmente foram obtidos os indicadores de graus-hora de resfriamento e comparados com valores das tabelas de classificação do regulamento. Considerando a temperatura-base para cálculo de $26{ }^{\circ} \mathrm{C}$, os indicadores de graus-hora de resfriamento obtidos na simulação resultaram em valores muito abaixo do máximo exigido para o nível A, que é de 2.310 . Assim, conforme descrito na Tabela 12, a edificação foi classificada em nível A para os três ambientes, sendo então nível A para a envoltória de verão, que corresponde a um equivalente numérico de resfriamento igual a 5 .

Para o modelo da edificação condicionada artificialmente foram obtidos os consumos de energia relativos para aquecimento $\left(\mathrm{C}_{\mathrm{A}}\right)$ e refrigeração $\left(C_{R}\right)$, apresentados na Tabela 12, e comparados com valores das tabelas de classificação do regulamento. Os dormitórios apresentaram resultados de $\mathrm{C}_{\mathrm{A}}$ abaixo do máximo permitido para o nível A $\left(15,591 \mathrm{kWh} / \mathrm{m}^{2} \mathrm{a}\right)$, enquanto a sala de estar apresentou um consumo de $23,17 \mathrm{kWh} / \mathrm{m}^{2} \mathrm{a}$, dentro da faixa de classificação para o nível B. Os resultados de consumo para refrigeração estão descritos na Tabela 13. Considerando que são apenas informativos, não são utilizados para determinar o nível de eficiência da envoltória.

O equivalente numérico de aquecimento da edificação é obtido através da ponderação dos equivalentes numéricos do consumo de aquecimento $\left(\right.$ EqNum $\left._{\mathrm{A}}\right)$ pelas áreas úteis dos ambientes avaliados $\left(\mathrm{AU}_{\mathrm{Amb}}\right)$, apresentados na Tabela 14.

Tabela 10 - Cenários para análise de consumo de energia

\begin{tabular}{l|c|c|c|c}
\hline \multicolumn{1}{c|}{ Cenários } & Descrição & $\begin{array}{c}\text { COP } \\
\text { Aquecimento }\end{array}$ & $\begin{array}{c}\text { COP } \\
\text { Refrigeração }\end{array}$ & Período \\
\hline Cenário 1 & $\begin{array}{c}\text { MVHR + climatização } \\
\text { artificial }\end{array}$ & $1 \mathrm{~W} / \mathrm{W}$ & $1 \mathrm{~W} / \mathrm{W}$ & Diurno e noturno \\
\hline \multirow{2}{*}{ Cenário 2 } & $\begin{array}{c}\text { Climatização artificial de } \\
\text { expansão direta }\end{array}$ & $3,0 \mathrm{~W} / \mathrm{W}$ & $2,75 \mathrm{~W} / \mathrm{W}$ & $21 \mathrm{~h} 00 \mathrm{~min}$ às $9 \mathrm{~h} 00 \mathrm{~min}$ \\
\cline { 2 - 5 } & Ventilação natural & - & - & $9 \mathrm{~h} 00 \mathrm{~min}$ às 21h00min \\
\hline
\end{tabular}


Tabela 11 - Cenários para a análise de desempenho térmico

\begin{tabular}{l|c|c|c}
\hline \multicolumn{1}{c|}{ Cenários } & Descrição & Setpoint & Período \\
\hline Cenário 1 & Ventilação natural & $20^{\circ} \mathrm{C}$ & Diurno e noturno \\
\hline \multirow{2}{*}{ Cenário 2 } & Climatização artificial & $22^{\circ} \mathrm{C}-24^{\circ} \mathrm{C}$ & $21 \mathrm{~h} 00 \mathrm{~min}$ às 9h00min \\
\cline { 2 - 4 } & Ventilação natural & $23^{\circ} \mathrm{C}$ & $9 \mathrm{~h} 00 \mathrm{~min}$ às 21h00min \\
\hline Cenário 3 & MVHR & $20^{\circ} \mathrm{C}-26^{\circ} \mathrm{C}$ & Diurno e noturno \\
\hline
\end{tabular}

Tabela 12 - Resultados de graus-hora de resfriamento

\begin{tabular}{l|c|c|c}
\hline \multicolumn{1}{c|}{ Ambiente } & GH $_{\text {Resfr }}$ & Nível de eficiência & EqNum $_{\text {Resfr }}$ \\
\hline Dormitório 1 & 0 & A & 5 \\
Dormitório 2 & 0,50 & A & 5 \\
Estar/Cozinha & 243,35 & A & 5 \\
\hline
\end{tabular}

Tabela 13 - Consumos de aquecimento e refrigeração do condicionador de ar

\begin{tabular}{c|c|c|c|c|c|c|c}
\hline Ambiente & $\begin{array}{c}\mathbf{A} \mathbf{U}_{\text {Amb }} \\
\left(\mathbf{m}^{\mathbf{2}}\right)\end{array}$ & $\begin{array}{c}\mathbf{C}_{\mathbf{A}} \\
\left(\mathbf{k W h} / \mathbf{m}^{\mathbf{2}} \mathbf{a}\right)\end{array}$ & $\begin{array}{c}\text { Nível de } \\
\text { eficiência }\end{array}$ & $\mathbf{E q N u m}_{\mathbf{A}}$ & $\begin{array}{c}\mathbf{C}_{\mathbf{R}} \\
\left(\mathbf{k W h} / \mathbf{m}^{\mathbf{2}} \mathbf{a}\right)\end{array}$ & $\begin{array}{c}\text { Nível de } \\
\text { eficiência }\end{array}$ & $\mathbf{E q N u m}_{\mathbf{R}}$ \\
\hline Dormitório 1 & 17,89 & 14,72 & $\mathrm{~A}$ & 5 & 5,87 & $\mathrm{~B}$ & 4 \\
Dormitório 2 & 12,41 & 11,04 & $\mathrm{~A}$ & 5 & 11,09 & $\mathrm{C}$ & 3 \\
Dormitório 3 & 94,41 & 23,17 & $\mathrm{~B}$ & 4 & 5,06 & $\mathrm{~A}$ & 1 \\
\hline
\end{tabular}

Tabela 14 - Ponderação dos equivalentes numéricos do consumo de aquecimento

\begin{tabular}{|c|c|c|c|c|c|}
\hline Ambiente & $\mathbf{A} \mathbf{U}_{\mathrm{Amb}}\left(\mathbf{m}^{2}\right)$ & $\begin{array}{c}\text { Área } \\
\text { ponderada }\end{array}$ & $\begin{array}{c}\text { Nível de } \\
\text { eficiência }\end{array}$ & $\mathbf{E q N u m}_{A}$ & $\begin{array}{c}\text { Ponderação } \\
\text { EqNum }_{\text {A }} \\
\end{array}$ \\
\hline Dormitório 1 & 17,89 & 0,14 & $\mathrm{~A}$ & 5 & 0,7 \\
\hline Dormitório 2 & 12,41 & 0,10 & A & 5 & 0,5 \\
\hline Estar/Cozinha & 94,41 & 0,76 & B & 4 & 3,04 \\
\hline \multicolumn{5}{|l|}{$\mathrm{EqNum}_{\mathrm{A}}$} & 4,24 \\
\hline
\end{tabular}

Assim, a pontuação 4,24 classifica o nível de eficiência da envoltória de inverno como nível B.

O equivalente numérico da envoltória da edificação é determinado por meio da equação 1 , apresentada anteriormente. $\mathrm{O}$ resultado encontrado

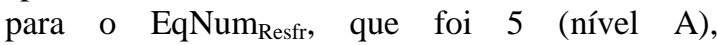
corresponde a $44 \%$ da pontuação final, e o resultado do EqNum $_{\mathrm{A}}$, que foi 4 , corresponde a $56 \%$. Assim, o resultado do equivalente numérico da envoltória foi 4,44 , que se encontra no intervalo entre 3,5 $\leq \mathrm{PT}<4,5$, classificando, portanto, o nível de eficiência da envoltória da edificação como nível $\mathrm{B}$.

\section{Avaliação da eficiência da envoltória considerando o uso do sistema de ventilação mecânica com recuperador de calor}

Neste modelo o nível de eficiência da envoltória da edificação foi determinado utilizando-se o sistema MVHR. Foram analisados os graus-hora de resfriamento, com temperatura-base de $26^{\circ} \mathrm{C}$, e os resultados encontrados, apresentados na Tabela 15 , se mantiveram abaixo do limite para o nível A do RTQ-R, que é de 2.310.

Também foi analisado o sobreaquecimento interior, onde, segundo a certificação Passive House, a temperatura não deve ultrapassar os 26 ${ }^{\circ} \mathrm{C}$ (climas quentes) em no máximo $10 \%$ das horas do ano.

Apesar de o valor de sobreaquecimento para o dormitório 2 ser superior ao estipulado pela Passive House numa análise global da edificação (e não por zona térmica), o valor obtido é inferior a $10 \%$.

Com o uso do sistema de ventilação com recuperador de calor, os resultados de consumo de aquecimento e refrigeração para os três ambientes (Tabela 16) apresentaram valores inferiores ao limite para o nível A do RTQ-R (de 15,591 $\mathrm{kWh} / \mathrm{m}^{2} \mathrm{a}$ para aquecimento e de $5,849 \mathrm{kWh} / \mathrm{m}^{2} \mathrm{a}$ para refrigeração)

Como a edificação foi classificada em nível A para o consumo de aquecimento e graus-hora de resfriamento, o nível de eficiência da envoltória da edificação é classificado como nível A. Os valores 
de consumo de refrigeração são apenas informativos (conforme o RTQ-R).

\section{Análise comparativa do consumo de energia entre o sistema condicionador de ar e a ventilação mecânica com recuperador de calor (MVHR)}

A Tabela 17 apresenta os resultados dos consumos de energia do sistema MVHR e do sistema de condicionador de ar de expansão direta, em que foram variados os setpoints para abertura de janelas progressivamente entre $20^{\circ} \mathrm{C}$ e $24^{\circ} \mathrm{C}$.

Analisando os resultados, pode-se perceber que o consumo de energia do sistema MVHR para climatizar os espaços em estudo é menor para aquecimento e refrigeração em todos os casos.

Em comparação com o sistema de condicionador de ar, configurado de acordo com o RTQ-R, com setpoint de ventilação de $20^{\circ} \mathrm{C}$, o uso do sistema MVHR permite uma redução de $56,63 \%$ do consumo de energia para aquecimento.

Variando o setpoint para a abertura de janelas progressivamente (Figura 8), conclui-se que a melhor solução encontrada foi com um setpoint de temperatura para abertura de janelas de $23{ }^{\circ} \mathrm{C}$, o qual, para manter as condições de conforto, apresentou consumo de $12,50 \mathrm{kWh} / \mathrm{m}^{2} \mathrm{a}$ para aquecimento e de $6,99 \mathrm{kWh} / \mathrm{m}^{2}$ a para refrigeração. Essa solução corresponde à mais equilibrada em termos de necessidade energética para ambas as estações.

O condicionador de ar consome mais energia para aquecimento quando configurado de acordo com o RTQ-R, com setpoint para abertura de janelas a 20 ${ }^{\circ} \mathrm{C}$. Conforme se aumenta o setpoint de abertura de janelas, os consumos para aquecimento reduzem progressivamente e o consumo de refrigeração aumenta, pois no verão é mais favorável a abertura de janelas com temperaturas mais baixas.

\section{Análise do desempenho térmico: temperaturas internas}

O desempenho térmico da edificação foi analisado com base nos intervalos de $20^{\circ} \mathrm{C}$ e $26{ }^{\circ} \mathrm{C}$, estabelecidos pela Passive House, para os três modelos: ventilado naturalmente, com sistema de condicionamento com expansão direta e com sistema MVHR.

\section{Modelo ventilado naturalmente}

Através da Figura 9 é possível analisar a variação das temperaturas internas em relação às externas do modelo ventilado naturalmente, com setpoint de $20^{\circ} \mathrm{C}$.

Tabela 15 - Resultados de graus-hora de resfriamento utilizando MVHR

\begin{tabular}{l|c|c|c|c}
\hline \multicolumn{1}{c|}{ Ambiente } & $\mathbf{G H}_{\text {Resfr }}$ & $\begin{array}{c}\text { Nível de } \\
\text { eficiência }\end{array}$ & EqNum $_{\text {Resfr }}$ & $\begin{array}{c}\text { Sobreaquecimento } \\
(\%)\end{array}$ \\
\hline Dormitório 1 & 103,04 & A & 5 & 8,58 \\
Dormitório 2 & 204,31 & A & 5 & 14,36 \\
Estar/Cozinha & 277,60 & A & 5 & 8,37 \\
\hline
\end{tabular}

Tabela 16 - Consumos de aquecimento e refrigeração do MVHR

\begin{tabular}{l|c|c|c|c|c|c|c}
\hline Ambiente & $\mathbf{A U}_{\mathbf{A m b}}\left(\mathbf{m}^{\mathbf{2}}\right)$ & $\begin{array}{c}\mathbf{C}_{\mathbf{A}} \\
\left(\mathbf{k W h} / \mathbf{m}^{\mathbf{2}} \mathbf{a}\right)\end{array}$ & $\begin{array}{c}\text { Nível de } \\
\text { eficiência }\end{array}$ & $\mathbf{E q N u m}_{\mathbf{R}}$ & $\begin{array}{c}\mathbf{C}_{\mathbf{R}} \\
\left(\mathbf{k W h} / \mathbf{m}^{\mathbf{2}} \mathbf{a}\right)\end{array}$ & $\begin{array}{c}\text { Nível de } \\
\text { eficiência }\end{array}$ & $\mathbf{E q N u m}_{\mathbf{A}}$ \\
\hline Dormitório 1 & 17,89 & 1,99 & $\mathrm{~A}$ & 5 & 1,72 & $\mathrm{~A}$ & 5 \\
Dormitório 2 & 12,41 & 1,10 & $\mathrm{~A}$ & 5 & 5,04 & $\mathrm{~A}$ & 5 \\
Estar/Cozinha & 94,41 & 9,24 & $\mathrm{~A}$ & 5 & 5,19 & $\mathrm{~A}$ & 5 \\
\hline
\end{tabular}

Tabela 17 - Consumos de aquecimento e refrigeração do MVHR e sistema de expansão direta (SED)

\begin{tabular}{c|c|c|c|c|c|c}
\hline Período & \multirow{2}{*}{$\mathbf{M V H R}^{\mathbf{1}}$} & $\begin{array}{c}\text { SED + Vent } \\
\mathbf{2 0}^{\mathbf{}} \mathbf{C}^{\mathbf{2}}\end{array}$ & $\begin{array}{c}\text { SED + Vent } \\
\mathbf{2 1}^{\mathbf{}} \mathbf{C}\end{array}$ & $\begin{array}{c}\text { SED + Vent } \\
\mathbf{2 2}^{\mathbf{}} \mathbf{C}\end{array}$ & $\begin{array}{c}\text { SED + Vent } \\
\mathbf{2 3}^{\mathbf{}} \mathbf{C}\end{array}$ & $\begin{array}{c}\text { SED + Vent } \\
\mathbf{2 4}^{\mathbf{}} \mathbf{C}\end{array}$ \\
\hline Aquecimento $\left(\mathrm{kWh} / \mathrm{m}^{2} \mathrm{a}\right)$ & 9,00 & 20,75 & 16,68 & 14,03 & 12,50 & 11,94 \\
Refrigeração $\left(\mathrm{kWh} / \mathrm{m}^{\mathbf{2}} \mathrm{a}\right)$ & 4,37 & 5,78 & 5,92 & 6,26 & 6,99 & 8,41 \\
\hline
\end{tabular}

Nota: Legenda:

MVHR = sistema de ventilação mecânica com recuperador de calor;

VENT = temperatura de abertura de janelas; e

SED = sistema de expansão direta. 
Figura 8 - Melhor solução para a abertura de janelas

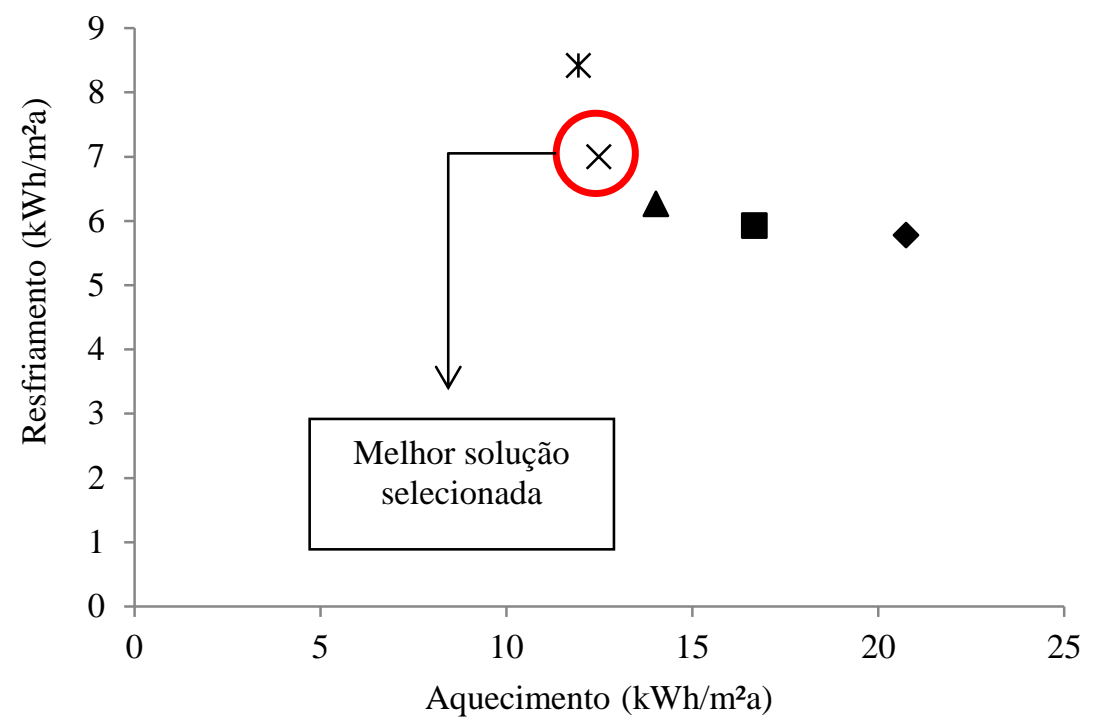

$\rightarrow \mathrm{SED}+\mathrm{Vent} 20^{\circ}$

$\left[\mathrm{kWh} /\left(\mathrm{m}^{2} \mathrm{a}\right)\right]$

SED + Vent $21^{\circ}$

$\left[\mathrm{kWh} /\left(\mathrm{m}^{2} \mathrm{a}\right)\right]$

$\Delta \mathrm{SED}+\mathrm{Vent} 22^{\circ}$

$\left[\mathrm{kWh} /\left(\mathrm{m}^{2} \mathrm{a}\right)\right]$

$\times$ SED+ Vent $23^{\circ}$

$\left[\mathrm{kWh} /\left(\mathrm{m}^{2} \mathrm{a}\right)\right]$

*SED + Vent $24^{\circ}$

$\left[\mathrm{kWh} /\left(\mathrm{m}^{2} \mathrm{a}\right)\right]$

Figura 9 - Variação das temperaturas internas com o uso de ventilação natural com setpoint de $20^{\circ} \mathrm{C}$ anual

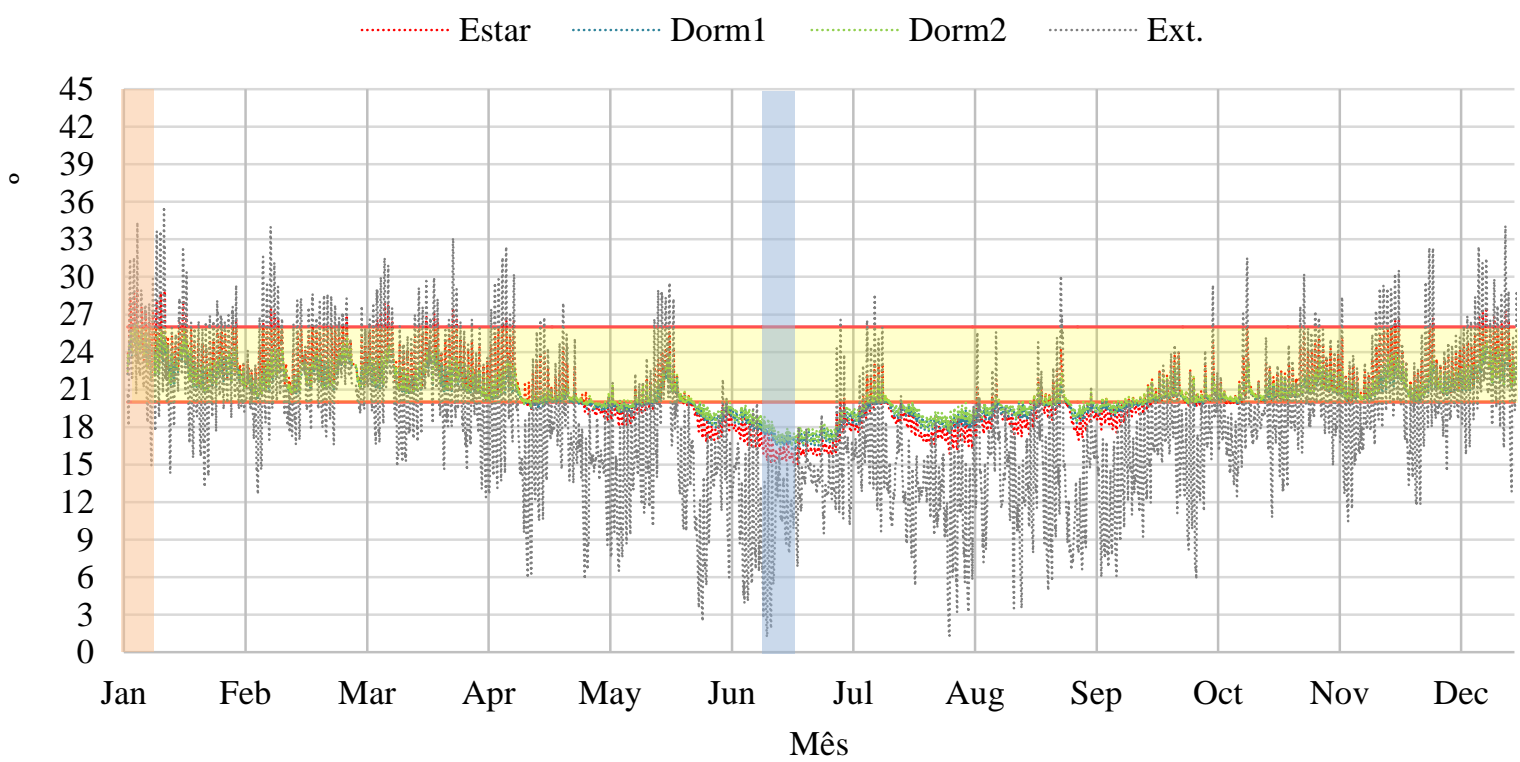

Durante o período frio, com destaque entre maio e setembro, as temperaturas internas permanecem baixas nas três zonas analisadas, na maior parte do tempo abaixo dos $20{ }^{\circ} \mathrm{C}$. Nesse período a edificação permanece sem renovação do ar interior devido às baixas temperaturas internas.

Durante o período mais quente, entre novembro e abril, as temperaturas internas permanecem na maior parte do tempo sem necessidade de climatização artificial, entre $20{ }^{\circ} \mathrm{C}$ e $26{ }^{\circ} \mathrm{C}$, com sobreaquecimento apenas na zona de estar/cozinha em $3,21 \%$ das horas do ano.
Através da análise anual das temperaturas externas foram identificados os períodos com as temperaturas mais severas e definidas as semanas extremas para verão (01/01 a 08/01) e inverno (08/06 a 16/06), representadas na Figura 9 pelas colunas verticais.

A Figura 10 representa a variação das temperaturas internas e externas na semana extrema de verão.

Pode-se perceber que a edificação ventila durante o período da manhã e à noite, quando as temperaturas internas estão maiores que $20^{\circ} \mathrm{C}$ e a temperatura externa está favorável. Durante a 
tarde, quando a temperatura externa é elevada, a edificação permanece sem ventilar, e a temperatura interna aumenta progressivamente, devido aos ganhos térmicos provenientes da radiação solar. Por isso, apresenta picos de temperatura durante a tarde, principalmente na zona de estar/cozinha, onde existem maiores superfícies envidraçadas e maior interface com o exterior.

Para o inverno (Figura 11) a semana extrema foi definida entre os dias 8 e 16 de junho, quando apresentou as temperaturas mais baixas.
Observou-se que para a semana mais severa de inverno todos os compartimentos se encontravam com uma temperatura interna de desconforto. Contudo, apesar do mau desempenho térmico da edificação, verificou-se que a amplitude diária apresenta baixas oscilações de temperatura. Como as temperaturas permanecem abaixo $\operatorname{dos} 20{ }^{\circ} \mathrm{C}$, não há renovação do ar interior dos ambientes.

Figura 10 - Variação das temperaturas internas com o uso de ventilação natural - semana de verão

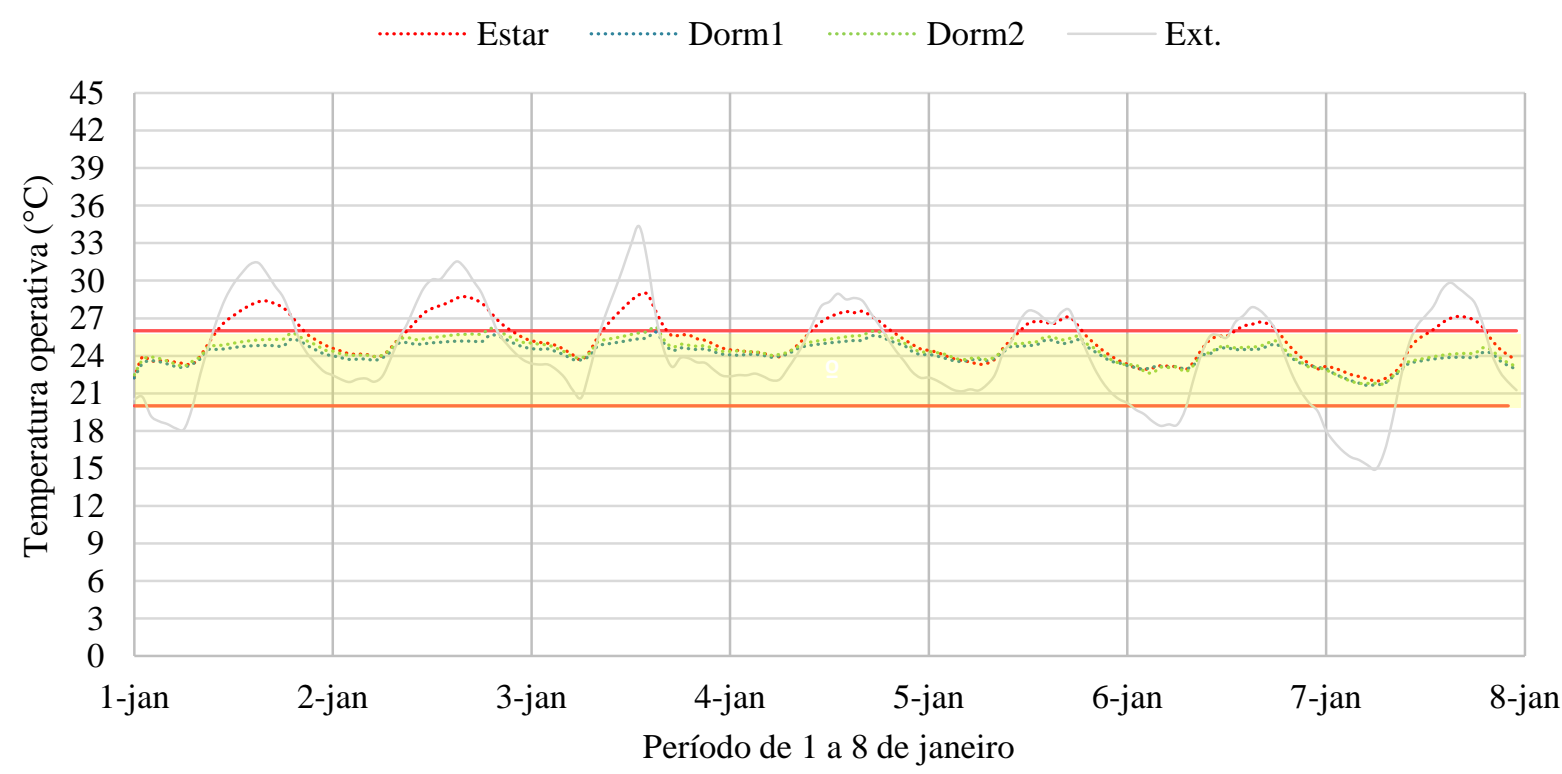

Figura 11 - Variação das temperaturas internas com o uso de VN com setpoint de $20^{\circ} \mathrm{C}$ - semana de inverno

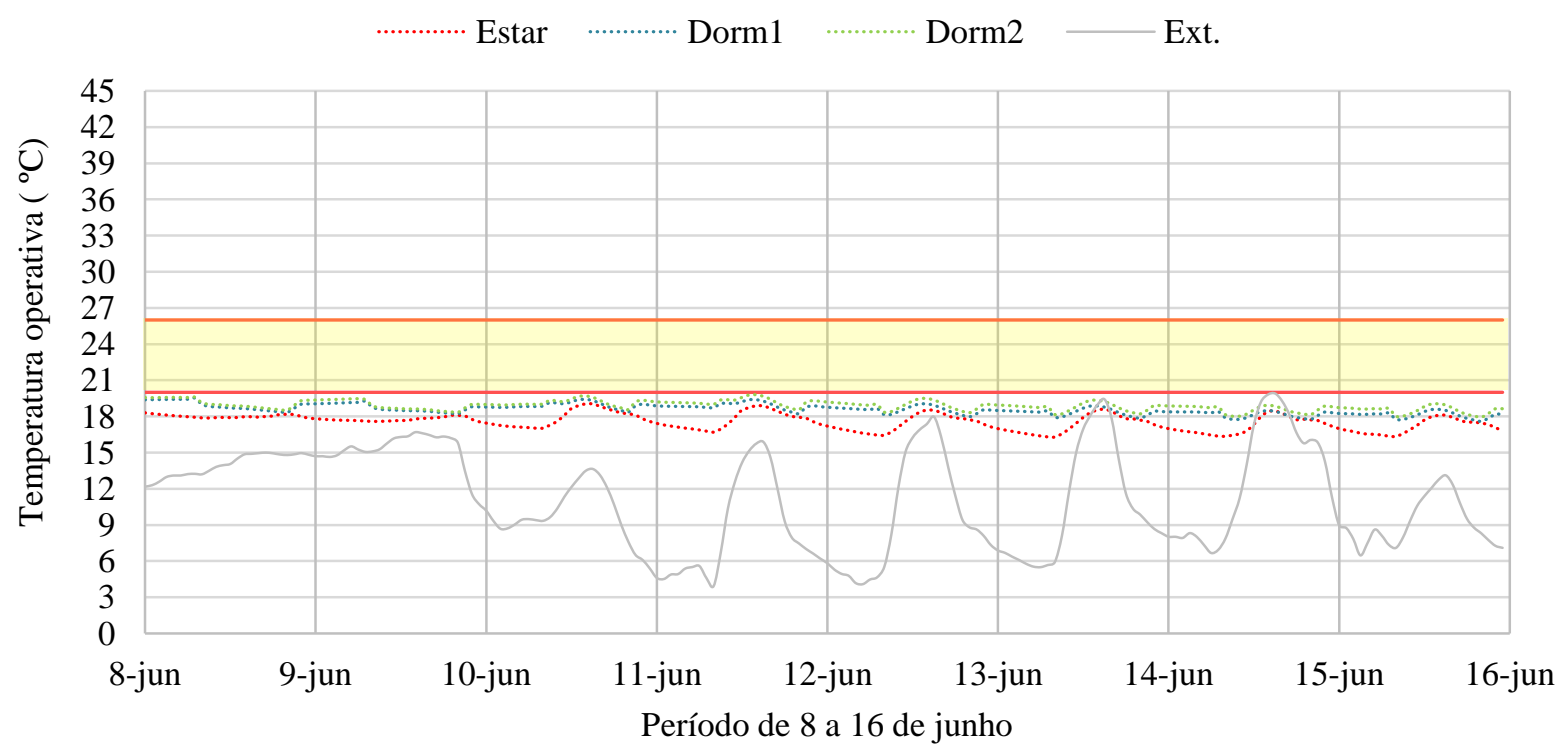


Analisando os fluxos de calor por superfícies opacas e translúcidas de um dia das semanas extremas, definidos como sendo o dia $1^{\circ}$ de janeiro para o verão e o dia 10 de junho para o inverno, é possível justificar que as maiores variações de temperatura na zona de estar/cozinha ocorrem devido a sua maior interface com o exterior e à maior área de superfícies envidraçadas.

Durante o dia de verão (Figura 12) a zona de estar/cozinha obteve aproximadamente $1.300 \mathrm{~W}$ de ganhos de calor por esquadrias durante as horas mais quentes do dia, enquanto os dormitórios apresentaram ganhos de calor de aproximadamente $100 \mathrm{~W}$.
Conforme a Figura 13, durante o dia de verão as superfícies opacas também contribuem para a variação da temperatura interior, visto que os ganhos de calor pelas superfícies opacas na zona de estar/cozinha foram de cerca de $4.000 \mathrm{~W}$ durante o dia, enquanto o dormitório 1 apresentou ganhos de cerca de $1.000 \mathrm{~W}$, e o dormitório 2, cerca de $500 \mathrm{~W}$. Durante a noite as superfícies opacas perdem calor para o exterior devido ao fato de a temperatura externa estar mais baixa. O ambiente de estar apresentou cerca de $3.000 \mathrm{~W}$ de perdas de calor, enquanto os dormitórios 1 e 2 apresentaram cerca de 600 e 300 respectivamente.

Figura 12 - Fluxos de calor por superfícies translúcidas - dia de verão

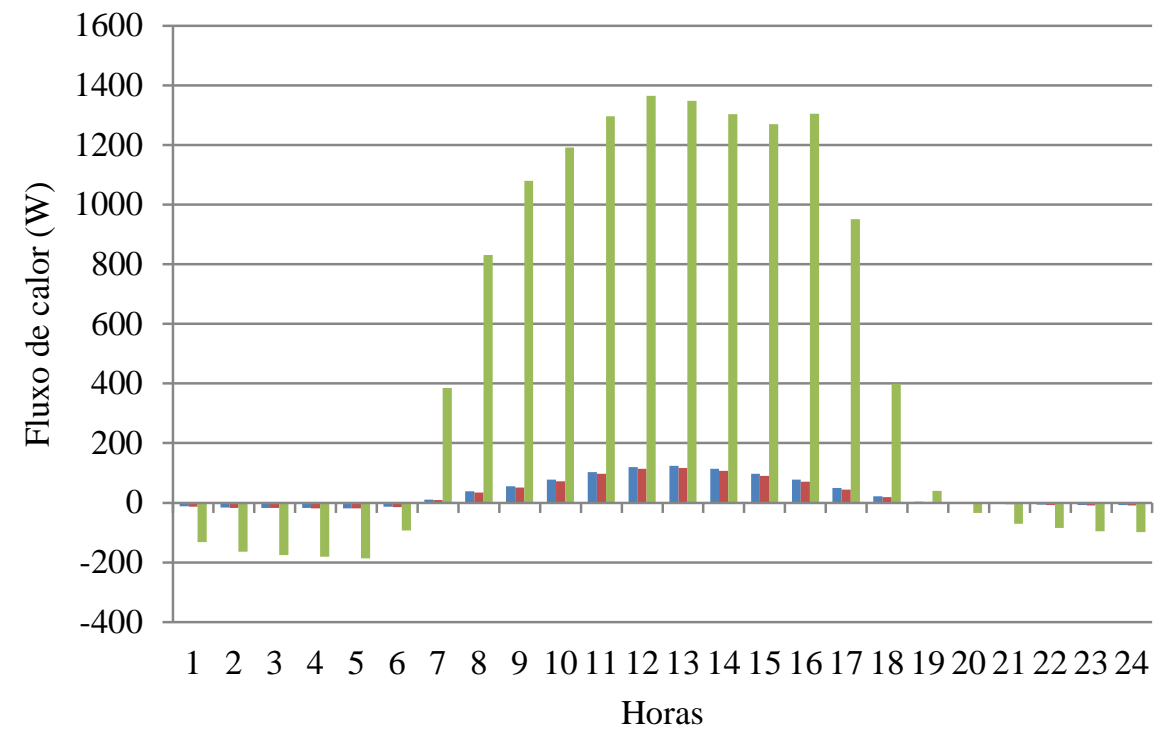

- Dorm 1 - Esquadrias

- Dorm 2 - Esquadrias

Estar - Esquadrias

Figura 13 - Fluxos de calor por superfícies opacas - dia de verão

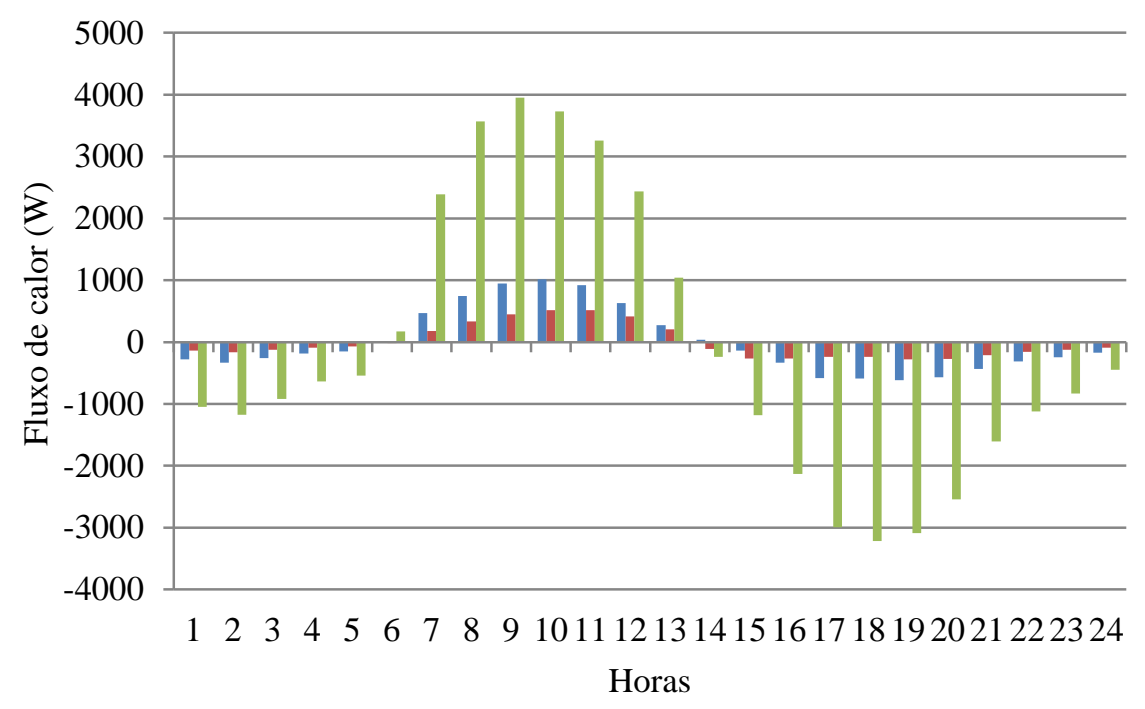

Dorm 1 -

Superficies opacas externas

- Dorm 2 -

Superficies opacas externas

Estar - Superficies opacas externas

216 Dalbem, R.; Cunha, E. G. da; Vicente, R.; Figueiredo, A. J.; Silva, A. C. S. B. da. 
Durante o dia de inverno as superfícies translúcidas (Figura 14) também apresentaram maiores ganhos de calor na zona de estar/cozinha, ultrapassando $2.000 \mathrm{~W}$ nas horas mais quentes, enquanto os dormitórios apresentaram cerca de $400 \mathrm{~W}$ de ganhos de calor. Durante a noite os ambientes perdem calor através das superfícies translúcidas, cerca de $400 \mathrm{~W}$ na zona de estar e cerca de $50 \mathrm{~W}$ nos dormitórios.

As superfícies opacas (Figura 15) pouco contribuem com os ganhos de calor no inverno, porém apresentam perdas de calor durante a noite, principalmente no ambiente de estar, devido à maior área de superfícies em contato com o exterior.

\section{Modelo com condicionador de ar e setpoint de ventilação natural de $23^{\circ} \mathrm{C}$}

O modelo a seguir apresentado (Figura 16) representa a solução com o melhor desempenho anual em termos de balanço energético, com o sistema de condicionador de ar de expansão direta (SED) durante a noite e ventilação natural durante o dia, com setpoint de temperatura de $23{ }^{\circ} \mathrm{C}$.

Observa-se que as temperaturas permanecem na zona de conforto durante a maior parte do ano, próximas a $26{ }^{\circ} \mathrm{C}$ durante o período quente $(31 / 10$ a 30/04). No período frio (30/04 a 31/10) as temperaturas permanecem próximas dos $20{ }^{\circ} \mathrm{C}$. Apenas foram verificados ligeiros períodos de desconforto na zona correspondente à sala de estar e cozinha.

Na Figura 17, da semana extrema de verão, o fato de a abertura de janelas ocorrer após se atingir a temperatura de $23{ }^{\circ} \mathrm{C}$ leva a que existam pequenos períodos de desconforto. No entanto, salienta-se que isso ocorreu apenas na sala de estar e durante a semana mais severa, não sendo representativo, portanto, da estação completa.

Durante a semana extrema de inverno (8 a 16 junho) as temperaturas permanecem acima dos 20 ${ }^{\circ} \mathrm{C}$ durante todo o tempo (Figura 18), dado que nunca se constatou a abertura de janelas para $o$ período apresentado devido ao fato de a temperatura exterior ser inferior a $23{ }^{\circ} \mathrm{C}$.

\section{Modelo com sistema de ventilação mecânica com recuperador de calor}

O modelo a seguir (Figura 19) apresenta a solução utilizando o sistema MVHR. As temperaturas internas se mantiveram dentro da zona de conforto, entre $20^{\circ} \mathrm{C}$ e $26^{\circ} \mathrm{C}$, para os três ambientes, e para isso o consumo de energia foi muito baixo.

Utilizando o sistema de ventilação com recuperador de calor, com setpoint de $20^{\circ} \mathrm{C}$ para aquecimento e $26{ }^{\circ} \mathrm{C}$ para resfriamento, e utilizando o sistema by-pass, as temperaturas (Figura 19) ficaram dentro da zona de conforto durante todo o ano nas três zonas. No período frio as temperaturas permaneceram próximas dos 20 ${ }^{\circ} \mathrm{C}$, com baixo consumo de energia. Durante o período mais quente as temperaturas ficaram próximas dos $26{ }^{\circ} \mathrm{C}$. Salienta-se que as necessidades energéticas de resfriamento podem baixar com a utilização de uma vazão de by-pass superior.

Figura 14 - Fluxos de calor por superfícies translúcidas - dia de inverno

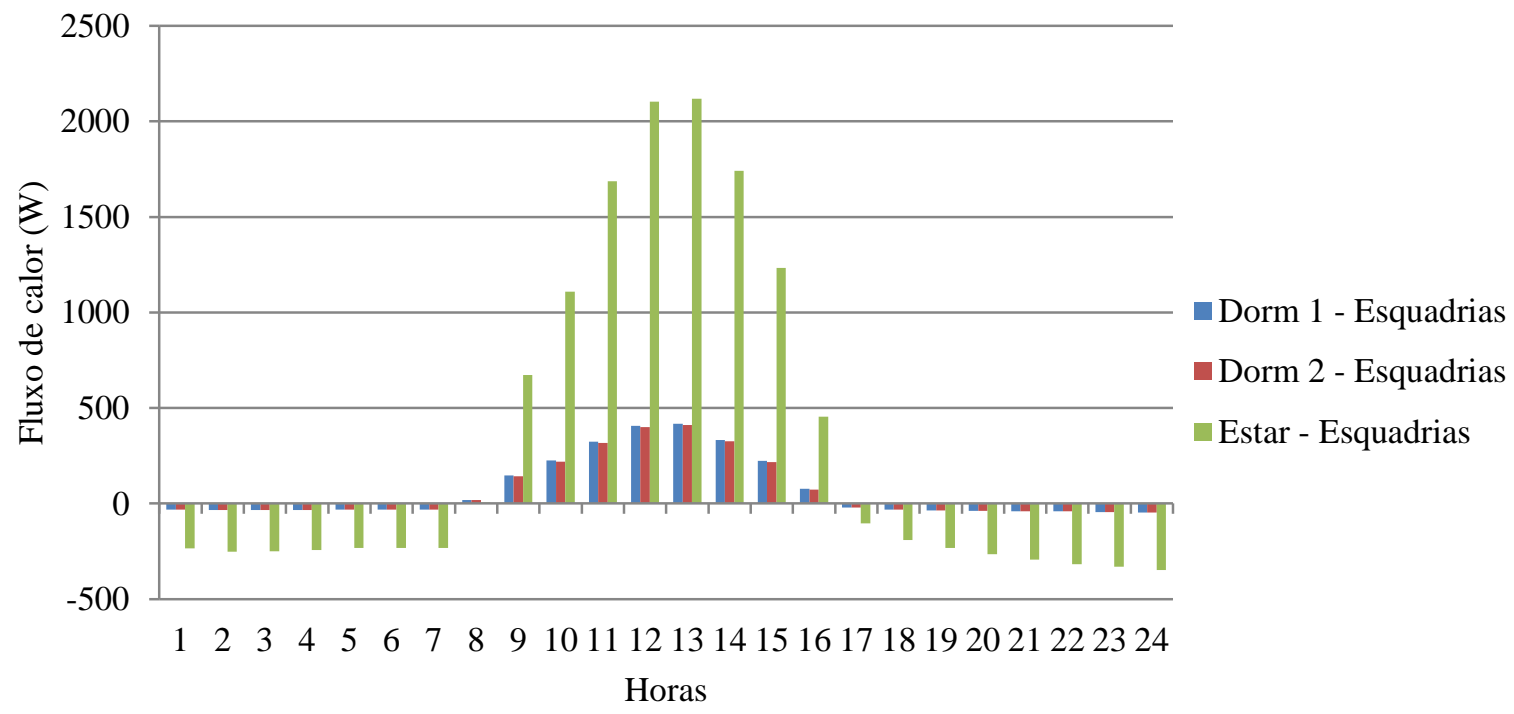

Discussão do desempenho da envoltória de uma passive house adaptada à zona bioclimática 2 em acordo com o 217 
Figura 15 - Fluxos de calor por superfícies opacas - dia de inverno

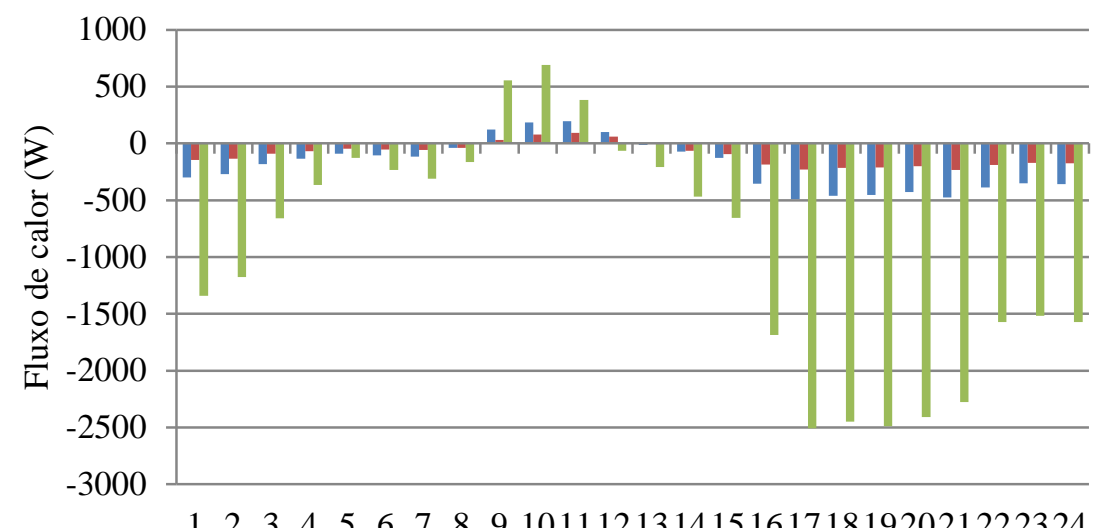

Dorm 1 -

Superficies opacas

externas

Superficies opacas

externas

opacas externas

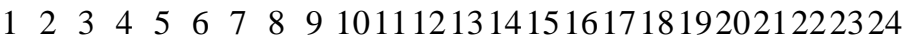

Horas

Figura 16 - Variação das temperaturas internas com o uso do SED e VN com setpoint de $23^{\circ} \mathrm{C}$ - anual

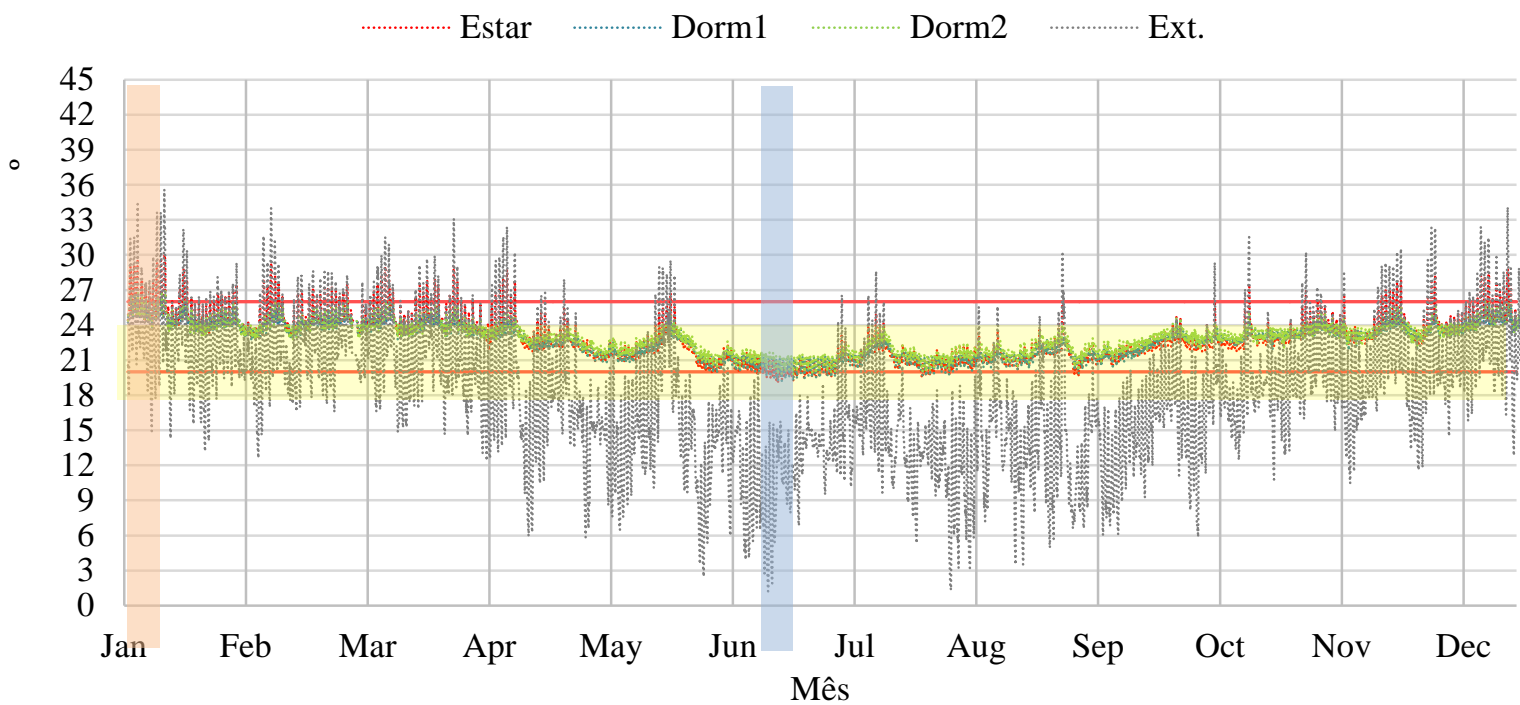

Figura 17 - Variação das temperaturas internas com o uso do SED e VN com setpoint de $23^{\circ} \mathrm{C}$ - semana de verão

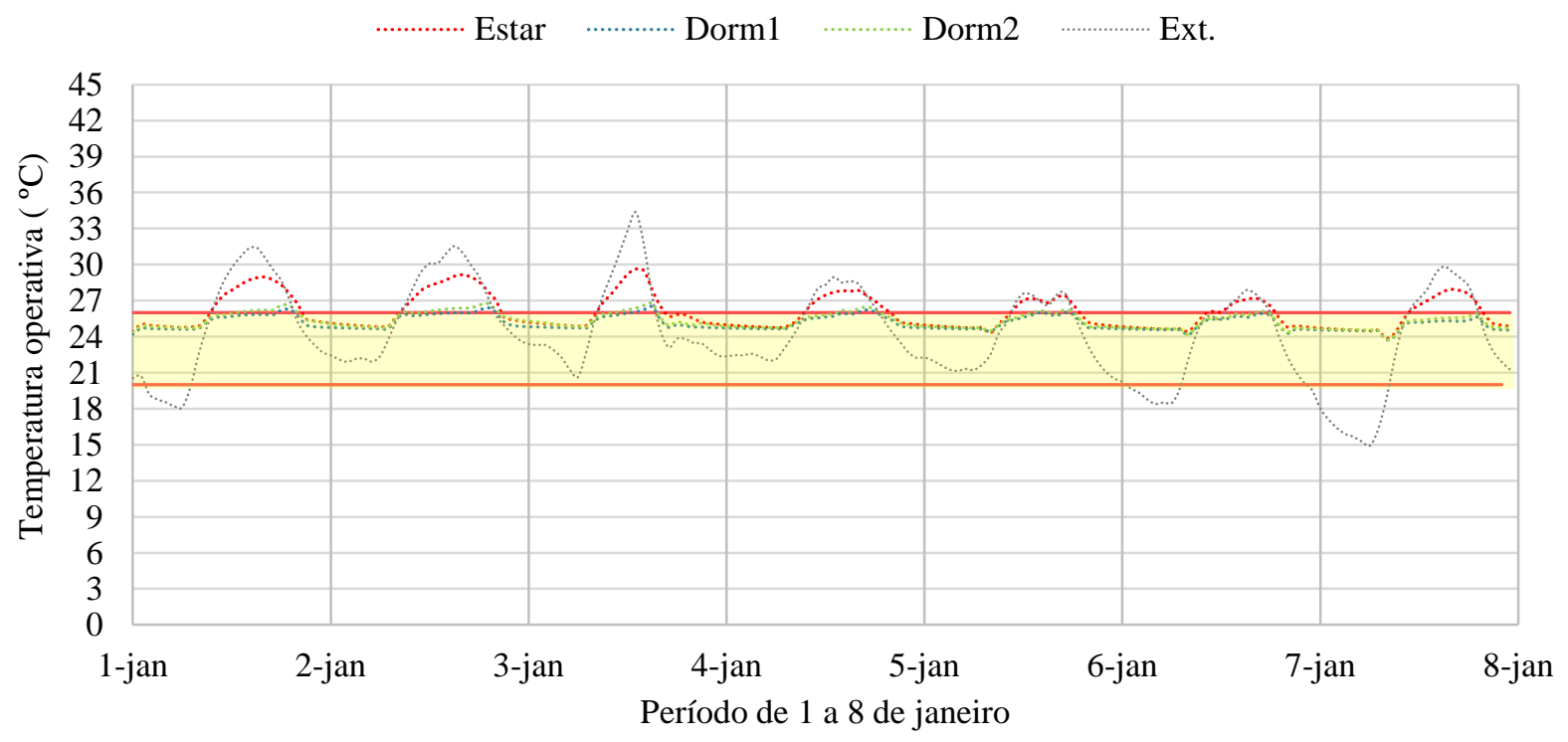

218 Dalbem, R.; Cunha, E. G. da; Vicente, R.; Figueiredo, A. J.; Silva, A. C. S. B. da. 
Figura 18 - Variação das temperaturas internas com o uso de SED e VN com setpoint de $23^{\circ} \mathrm{C}$ - semana de inverno

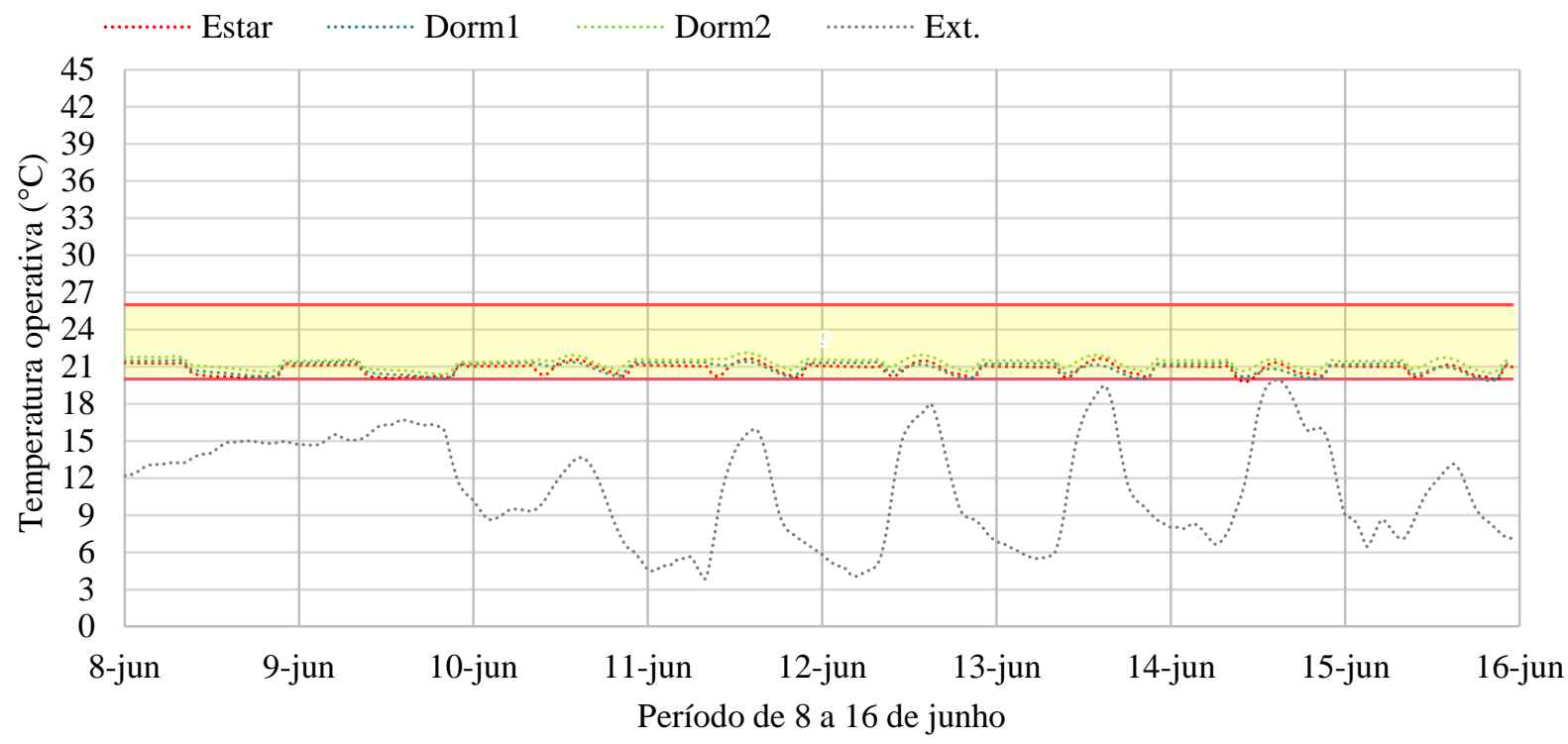

Figura 19 - Variação das temperaturas internas com o uso de MVHR - anual

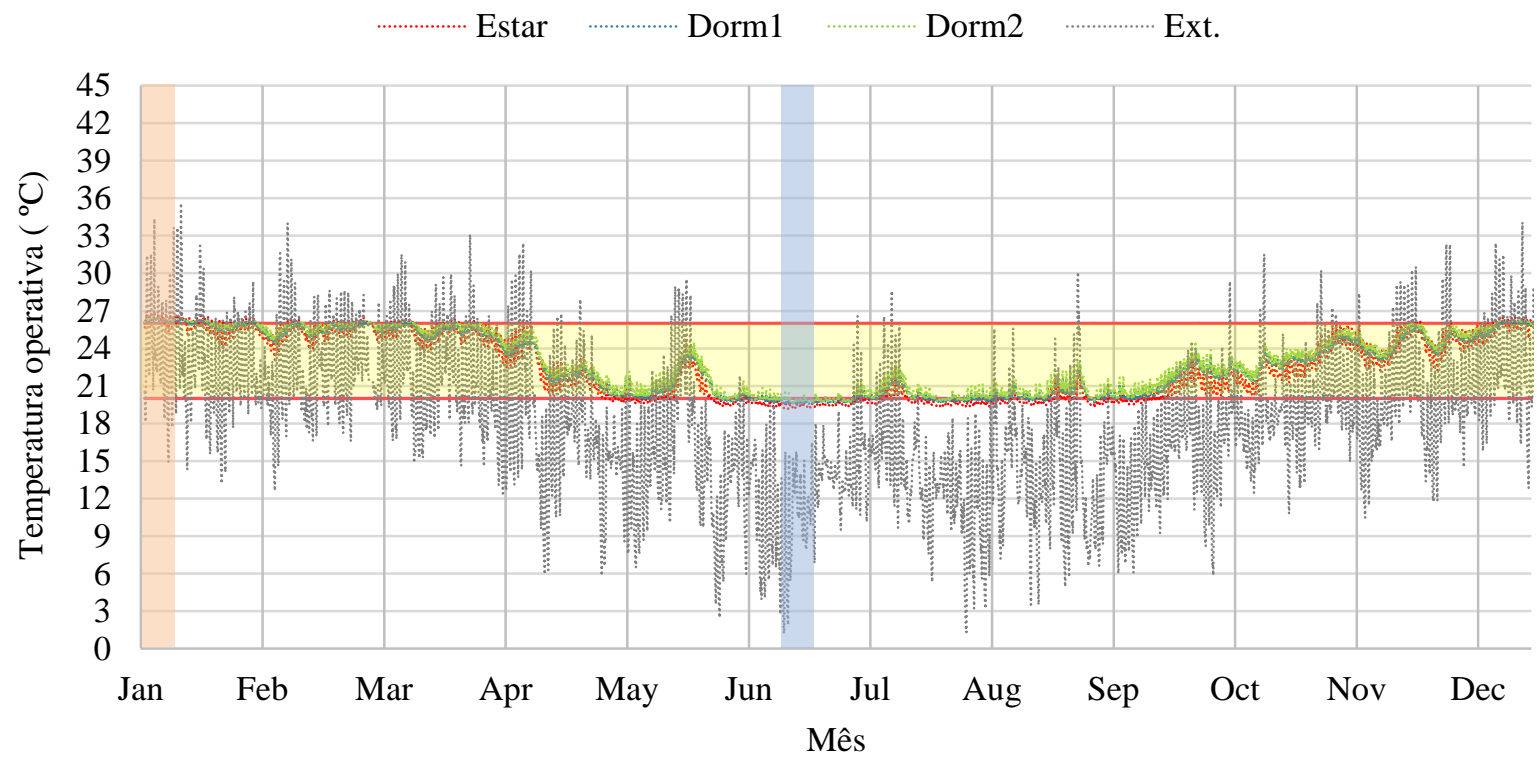

A Figura 20 apresenta as variações de temperaturas internas durante a semana extrema de verão, quando se pode perceber que as temperaturas permanecem constantes nos três ambientes, próximas a $26^{\circ} \mathrm{C}$.

Durante a semana de inverno (Figura 21) as temperaturas internas permaneceram próximas dos $20{ }^{\circ} \mathrm{C}$.

Como conclusão geral sobre esse sistema, verificou-se que a amplitude térmica diária é muito baixa (na ordem de $2{ }^{\circ} \mathrm{C}$ ) e que as temperaturas durante o período frio se encontram sobre o eixo de $20^{\circ} \mathrm{C}$, e no período quente, junto ao eixo de 26 ${ }^{\circ} \mathrm{C}$.

Também é importante destacar que o uso de ventilação mecânica com recuperador de calor assegura a renovação do ar, garantindo a qualidade do ar interior. 
Figura 20 - Variação das temperaturas internas com o uso de MVHR - semana de verão

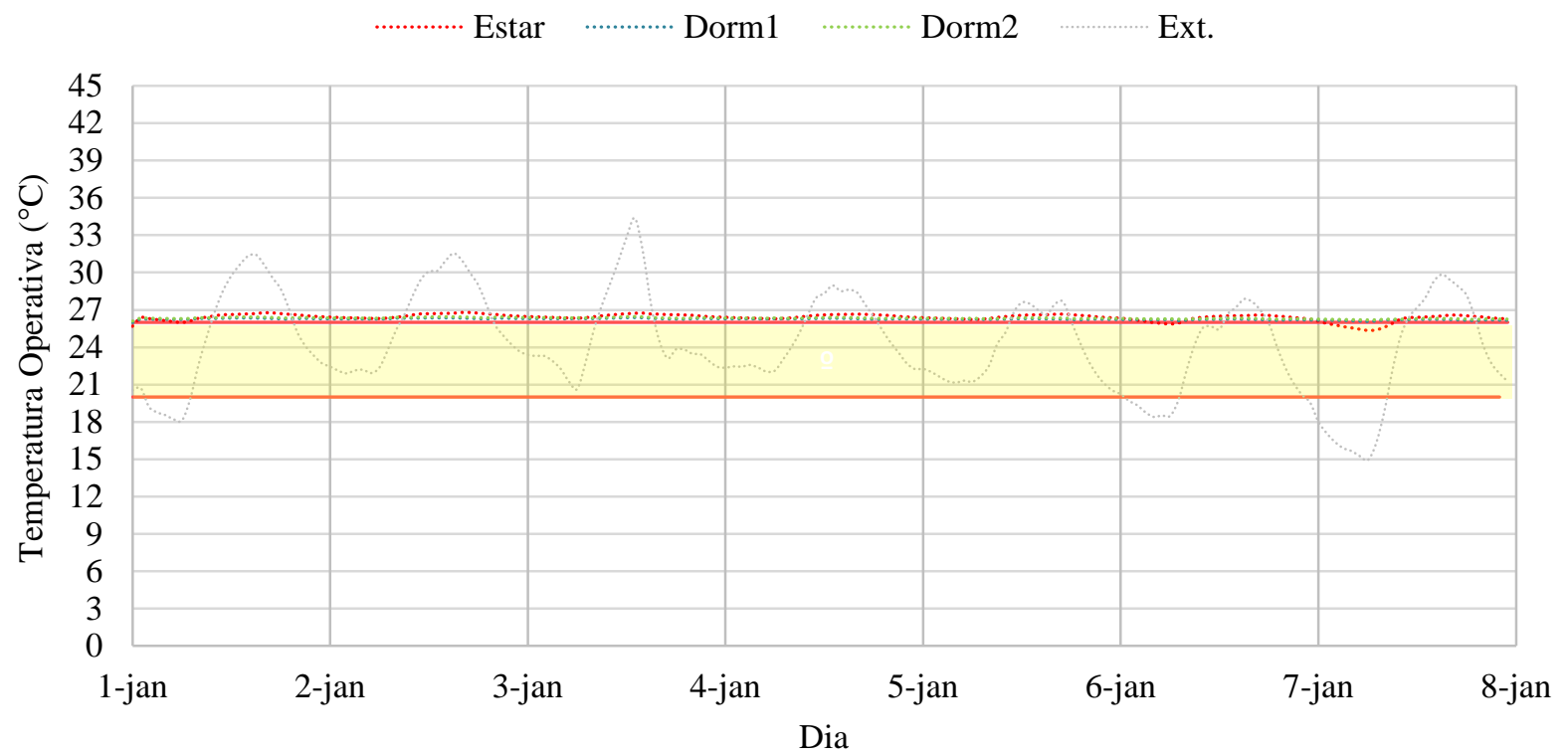

Figura 21 - Variação das temperaturas internas com o uso de MVHR - semana de inverno

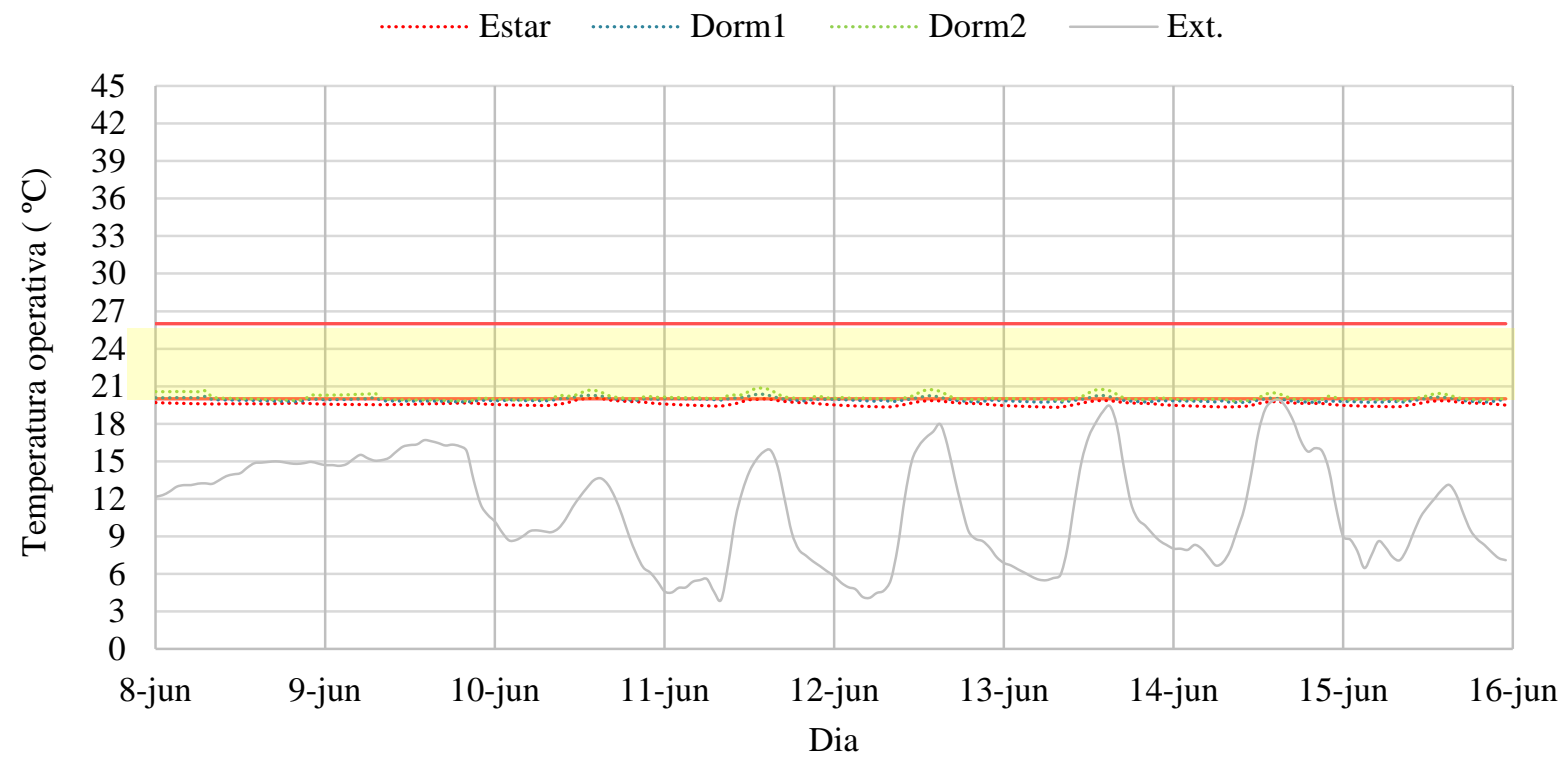

\section{Conclusões}

Com este trabalho conclui-se que é possível aplicar o conceito Passive House à cidade de Pelotas, Zona Bioclimática brasileira 2, adequando o projeto aos conceitos estabelecidos e utilizando valores menos exigentes de transmitância térmica da envoltória opaca e fechamentos transparentes em relação aos recomendados para climas frios.

A edificação apresentou um bom desempenho para o modelo ventilado naturalmente no verão, justificado pelo baixo número de graus-hora de resfriamento, porém durante o inverno é necessário o uso de um sistema de climatização mecânico devido às baixas temperaturas internas. Com o uso de condicionador de ar durante a noite e a abertura de janelas a um setpoint de $20{ }^{\circ} \mathrm{C}$, como recomenda o RTQ-R, a envoltória da edificação obteve classificação nível $\mathrm{B}$, conforme $\mathrm{O}$ regulamento brasileiro, devido ao consumo de aquecimento. Uma solução possível é a alteração do setpoint de abertura de janelas para uma temperatura de $23^{\circ} \mathrm{C}$, o que reduz o consumo para aquecimento no inverno, porém aumenta o consumo de refrigeração no verão. Uma segunda alternativa é o uso de um sistema de ventilação mecânica com recuperador de calor. A eficiência desse sistema reduz os consumos de aquecimento, 
além de garantir a qualidade do ar interior, em decorrência da alta estanqueidade da edificação.

Ainda existem desafios para a implantação do conceito Passive House no Brasil, como encontrar soluções construtivas e componentes que atendam às exigências da certificação. Também existe a necessidade de novos estudos a fim de analisar a integração do sistema de ventilação mecânica com ventilação natural ao longo dos diferentes períodos no ano, com o objetivo de reduzir o consumo para resfriamento.

Há ainda a necessidade de ampliar a discussão para as demais zonas bioclimáticas brasileiras e analisar a viabilidade econômica, o custo inicial para construção e a economia de energia ao longo de sua utilização.

\section{Referências}

ASSOCIAÇÃO BRASILEIRA DE NORMAS TÉCNICAS. NBR 15220: desempenho térmico para edificações de interesse social. Rio de Janeiro, 2005.

DALBEM, R.; FREITAS, J. M. R.; CUNHA, E. G. Conceito Passivhaus Aplicado ao Clima Brasileiro. Revista de Arquitetura IMED, v. 4, n. 1, p. 2636, 2015.

EL FOUIH, Y. et al. Adequacy of Air-to-Air Heat Recovery Ventilation System Applied in Low Energy Buildings. Energy and Buildings, v. 54, p. 29-39, 2012.

EMPRESA DE PESQUISA ENERGÉTICA. Balanço Energético Nacional 2015. Disponível em:

<https://ben.epe.gov.br/downloads/Relatorio_Final _BEN_2015.pdf>. Acesso em: 5 jul. 2016.

FIGUEIREDO, A. et al. Thermal Comfort and Energy Performance: sensitivity analysis to apply the Passive House concept to the Portuguese climate. Building and Environment, v. 103, p. 276-288, 2016.

FIGUEIREDO, A.; KAMPF, J; VICENTE, R. Passive House Optimization for Portugal: overheating evaluation and energy performance. Energy and Buildings, v. 118, p. 181-196, 2016.

GUSTAFSSON, M. et al. Energy Performance Comparison of Three Innovative HVAC Systems for Renovation Through Dynamic Simulation. Energy and Buildings, v. 82, p. 512-519, 2014.

INTERNATIONAL ORGANIZATION FOR STANDARDIZATION. EN 13829: thermal performance of building: determination of air permeability of buildings: fan pressurization method. Geneva, 2002.
INSTITUTO NACIONAL DE METROLOGIA, NORMALIZAÇÃO E QUALIDADE INDUSTRIAL. Regulamento Técnico da Qualidade para o Nível de Eficiência Energética de Edificações Residenciais, RTQ-R. Eletrobrás, Inmetro, 2012.

INTERNATIONAL ENERGY AGENCY. IEA

Energy Atlas. Disponível em:

<http://energyatlas.iea.org/?subject=-1002896040>. Acesso em: 10 mar. 2016a.

INTERNATIONAL ENERGY AGENCY. Net Zero Energy Solar Buildings. Disponível em: <http://task40.iea-shc.org/>. Acesso em: 10 mar. $2016 b$.

INTERNATIONAL PASSIVE HOUSE

ASSOCIATION. Active for More Comfort: Passive House. Darmstadt, v. 2, 2014.

LAMBERTS, R.; DUTRA, L.; PEREIRA, F. O. R. Eficiência Energética na Arquitetura. 3. ed. São Paulo: ProLivros, 2014.

MCLEOD, R.; MEAD, K.; STANDEN, M. Passivhaus Primer: designer's guide: a guide for the design team and local authorities. Disponível em:

<http://www.passivhaus.org.uk/filelibrary/Primers/ KN4430_Passivhaus_Designers_Guide_WEB.pdf >. Acesso em: 10 mar. 2016.

PACHECO, M. T. G. Ventilação Natural e Climatização Artificial: crítica ao modelo superisolado para residências de energia zero em Belém e Curitiba. Florianópolis, 2013. Tese (Doutorado em Engenharia Civil) - Escola de Engenharia, Universidade Federal de Santa Catarina, Florianópolis, 2013.

PARLAMENTO EUROPEU E CONSELHO DA UNIÃO EUROPEIA. Directiva 2010/31/UE do Parlamento Europeu e do Conselho de 19 de Maio de 2010 Relativa ao Desempenho Energético dos Edifícios (Reformulação). Jornal Oficial da União Europeia, 2010.

PASSIPEDIA. PHPP - Passive House Planning

Package. Disponível em:

$<$ http://passipedia.org/planning/calculating_energy _efficiency/phpp_-

_the_passive_house_planning_package>. Acesso em: 10 mar. 2016 .

PASSIPEDIA. The World's First Passive House, Darmstadt-Kranichstein, Germany. Disponível em:

$<$ http://passipedia.org/examples/residential_buildin gs/single_-

_family_houses/central_europe/the_world_s_first_ passive_house_darmstadt-kranichstein_germany>. Acesso em: 10 mar. 2016b. 
PASSIVE HOUSE INSTITUTE. Certified

Passive House: certification criteria for residential Passive House buildings. 2013. Disponível em: <http://passiv.de/downloads/03_certification_criter ia_residential_en.pdf $>$. Acesso em: 10 mar. 2016.

PASSIVE-ON PROJECT. A Norma Passivhaus Directrizes de Projecto Para Casas

Confortáveis de Baixo Consumo Energético: revisão de casas confortáveis de baixo consumo energético. Julho, 2007.

PBE EDIFICA. Tabelas de Classificação Pelo MÉTODO DE SIMulação. Disponível em: <http://www.pbeedifica.com.br/etiquetagem/reside ncial/simulacao>. Acesso em: 10 mar. 2016.
POUEY, J. A-A. Projeto de Edificação

Residencial Unifamiliar Para a Zona

Bioclimática 2 Com Avaliação Termo

Energética Por Simulação Computacional.

Pelotas, 2011. Dissertação (Mestrado em

Arquitetura) - Programa de Pós-Graduação em

Arquitetura e Urbanismo, Universidade Federal de Pelotas, Pelotas, 2011.

\section{WASSOUF, M. Da Casa Passiva à Norma}

Passivhaus: a arquitetura passiva em climas quentes. Barcelona: Gustavo Gili, 2014.

\section{Agradecimentos}

Os autores expressam seus agradecimentos à Fundação de Amparo à Pesquisa do Rio Grande do Sul (Fapergs), pelo auxílio à realização da pesquisa.

Renata Dalbem

Faculdade de Arquitetura e Urbanismo | Universidade Federal de Pelotas | Rua Benjamim Constant, 1359, Campus Porto, Centro |

Pelotas - RS - Brasil | CEP 96010-020 | Tel.: (53) 3284-5501 Ramal 5503 | E-mail: renata_dalbem@hotmail.com

Eduardo Grala da Cunha

Faculdade de Arquitetura e Urbanismo | Universidade Federal de Pelotas | E-mail: eduardogralacunha@yahoo.com.br

Romeu Vicente

Departamento Engenharia Civil | Universidade de Aveiro | Campus Universitário de Santiago, 3810 - 193 | Aveiro - Portugal | Tel.: +(351) 2 3437-0845 | E-mail: romvic@ua.pt

António José Figueiredo

Departamento Engenharia Civil | Universidade de Aveiro | E-mail: ajfigueiredo@ua.pt

Antônio César Silveira Baptista da Silva

Departamento de Tecnologia da Construção, Faculdade de Arquitetura e Urbanismo | Universidade Federal de Pelotas | Tel.: (53) 32845500 | E-mail: antoniocesar.sbs@gmail.com

Revista Ambiente Construído

Associação Nacional de Tecnologia do Ambiente Construído

Av. Osvaldo Aranha, $99-3^{\circ}$ andar, Centro

Porto Alegre - RS - Brasil CEP $90035-190$

Telefone: +55 (51) 3308-4084

Fax: +55 (51) 3308-4054

www.seer.ufrgs.br/ambienteconstruido

E-mail: ambienteconstruido@ufrgs.br 